\title{
Regulatory T-cells at the interface between human host and pathogens in infectious diseases and vaccination
}

\author{
Mardi C. Boer, Simone A. Joosten and Tom H. M. Ottenhoff* \\ Department of Infectious Diseases, Leiden University Medical Center, Leiden, Netherlands
}

Regulatory T-cells (Tregs) act at the interface of host and pathogen interactions in human infectious diseases. Tregs are induced by a wide range of pathogens, but distinct effects of Tregs have been demonstrated for different pathogens and in different stages of infection. Moreover, Tregs that are induced by a specific pathogen may non-specifically suppress immunity against other microbes and parasites. Thus, Treg effects need to be assessed not only in homologous but also in heterologous infections and vaccinations.

Edited by:

Amy Rasley,

Lawrence Livermore National

Laboratory, USA

Reviewed by:

Alexis DeHaven Dunkle,

Genentech, USA

Paolo Puccetti,

University of Perugia, Italy

*Correspondence:

Tom H. M. Ottenhoff, Department of Infectious Diseases, Leiden University Medical Center, Albinusdreef 2, 2333 ZA Leiden,

Netherlands

t.h.m.ottenhoff@/umc.nl

Specialty section:

This article was submitted to Microbial Immunology, a section of the journal Frontiers in Immunology

Received: 26 February 2015

Paper pending published: 16 March 2015

Accepted: 20 April 2015

Published: 11 May 2015

Citation:

Boer MC, Joosten SA and Ottenhoff THM (2015) Regulatory

T-cells at the interface between

human host and pathogens in infectious diseases and vaccination.

Front. Immunol. 6:217.

doi: 10.3389/fimmu.2015.00217 increase the risk of pathogen persistence and chronic disease, and the possibility of disease reactivation later in life. Mycobacterium leprae and Mycobacterium tuberculosis, causing leprosy and tuberculosis, respectively, are among the most ancient microbes known to mankind, and are master manipulators of the immune system toward tolerance and pathogen persistence. The majority of mycobacterial infections occur in settings coendemic for viral, parasitic, and (other) bacterial coinfections. In this paper, we discuss recent insights in the activation and activity of Tregs in human infectious diseases, with emphasis on early, late, and non-specific effects in disease, coinfections, and vaccination. We highlight mycobacterial infections as important models of modulation of host responses and vaccine-induced immunity by Tregs.

Keywords: regulatory T-cells, human regulatory T-cells, infection, vaccination, pathogens, tuberculosis, leprosy, BCG

\section{Introduction}

A myriad of innate and adaptive immune regulatory cells is induced upon infection, including cells of different lineages: regulatory-like macrophages, dendritic cells (DCs), NKT-cells, T-cells, B-cells, neutrophils, and mesenchymal stem cells. During the last decade, many reports have described the role of regulatory T-cells (Tregs) in infectious diseases and following vaccination. In infectious diseases, Tregs play a dual role: they benefit the host by limiting immune-mediated pathology and also facilitate chronic pathogen persistence by reducing effector immunity and clearance of infection (1). During acute infection, the beneficial role of Tregs seems to predominate, by regulating leukocyte in- and efflux into lymph nodes (LN) and infected sites, suppression of proliferation of infected cells, and favoring memory formation by increasing the time window of antigen availability.

Regulatory T-cells can be induced either in an antigen- and T-cell receptor (TCR)-dependent or in an antigen- and TCR-independent manner $(2,3)$. Specificity for self- or pathogen-derived 
antigens (or dual-specificity) was originally used to divide Treg populations into "natural" resp. "adaptive" Tregs, but it was recently recommended to denote Treg populations by place of induction: "thymus derived" or "peripherally derived," or when the origin is unclear "Foxp $3^{+}$Treg cell" (4). Designations of human Tregs are, however, complicated by the fact that, unlike murine Tregs, unique markers are lacking. In addition, non-Treg populations can express "Treg markers" such as Foxp3 and CD25 upon activation; therefore, human Tregs are preferably defined by multiple regulatory markers and/or by demonstrating suppressive activity (5). Human $\mathrm{CD}^{+}$Tregs have been studied much less than $\mathrm{CD}^{+}{ }^{+}$Tregs (5), even though they were among the first described "suppressor cells," especially in mycobacterial infections $(6,7)$. The relative lack in studies on human $\mathrm{CD}^{+}$Tregs is possibly the result of technical difficulties in isolating and assessing functions of $\mathrm{CD}^{+}$T-cells (8). Notwithstanding, $\mathrm{CD} 8^{+}$Tregs are re-emerging as important players in general, including in human infectious disease and following vaccination (5).

Once activated, Tregs can suppress pro-inflammatory cells through several mechanisms that are adaptable to the local environment (9). These mechanisms can mostly be divided into inhibitory cytokine production (either membrane-bound or by their release in the pericellular environment), suppression by cytolysis, metabolic disruption of pro-inflammatory cells, modulation of antigen-presenting cells (APCs), and the activity of certain Treg membrane expressed molecules (see below) (10). These mechanisms indeed support the concept that antigen specifically induced Tregs can cross-suppress also other cells irrespective of the presence of their cognate antigen or specificity, e.g., through the secretion of cytokines (5). This "bystander" or heterologous suppression can compromise immunity toward unrelated pathogens, as has been described for coinfection by helminths in diseases such as malaria and tuberculosis (TB) (11). Helminth coinfections can also impair the immunogenicity of vaccines such as (oral) cholera vaccination and (intradermal) BCG (Mycobacterium bovis bacillus Calmette-Guérin) and tetanus vaccination (12). Several Treg-expressed molecular markers have now been implicated directly in mediating suppression, such as cytotoxic T-lymphocyte-associated antigen 4 (CTLA-4), which modulates APCs via its ligands CD80 and CD86. Tregs were shown to use trans-endocytosis of CD80 and CD86, followed by their intracellular degradation, thereby relatively depleting the APC's expression of essential co-stimulatory receptors for T-cell CD28 ligation (13). In addition, the ecto-enzyme CD39 (E-NTPDase1), which is a relatively recently discovered Treg marker, exerts its suppressive effects through breakdown of adenosine triphosphate (ATP) (14).

In this paper, we will discuss the induction of Tregs (both specific and non-specific) by various pathogens as well as the functional implications of $\mathrm{CD}^{+}$and $\mathrm{CD} 8^{+}$Tregs in acute vs. chronic infectious diseases. We will discuss the role of Tregs in coinfections and highlight in particular infections with $M$. leprae and M. tuberculosis (Mtb), which are master manipulators of the human innate and adaptive immune response through the induction of regulatory circuits. We will discuss how the balance of pro- vs. anti-inflammatory responses could ultimately regulate pathogen persistence, and impact on the development of active vs. latent or reactivation of disease. We will also discuss the impact of
Tregs on diagnosis and treatment of TB, as well as their possible impact on vaccination against TB.

\section{Mechanisms of Treg Induction by Pathogens}

As a first line of host-defense against infection, the activation of innate immune cells through pattern recognition receptors (PRRs), such as Toll-like receptors (TLRs), lectin receptors, retinoic acid-inducible gene (RIG) receptors, scavenger, and phagocytic receptors, activates these cells to phagocytose and process the pathogen, after which they migrate to the draining lymph node (DLN) and present antigen to prime naïve T-cells. These cells then can differentiate into various classes of T-helper cells (Th), cytotoxic T-cells, or Tregs. Further activation and differentiation signals are provided to the T-cells upon migration into the infected tissue; these signals originate from other T-cells, activated tissueresident APCs, or even directly from the pathogen (see below). Tissue-resident, circulating, and migrating APCs comprised heterogeneous populations, and the activation of APCs can lead to the induction of pro-inflammatory or regulatory, homeostatic Tcell responses (15): for example, pro-inflammatory human type1 macrophages promote Th1-immunity and are characterized by IL-23 production and secretion of IL-12 after IFN $\gamma$ stimulation, whereas type- 2 macrophages poorly express co-stimulatory molecules, produce IL-10, and induce Tregs $(16,17)$.

Modulation of macrophages and DCs toward tolerogenic subsets has been described for various pathogens: after in vitro treatment of human DCs with Japanese encephalitis virus or Mtb, DCs upregulated the inhibitory receptor PD-L1, which induced the expansion of Tregs through PD-1 ligation (18-20). These effects were mediated by the Mtb-derived protein Acr (HspX Rv2031c), which is expressed during latency: Acr induced expression of PD-L1, TIM3, IDO, and IL-10 by murine DCs and promoted the induction of $\mathrm{CD} 4^{+} \mathrm{CD} 25^{+}$Foxp $3^{+}$T-cells (21). Furthermore, APCs can be modulated through alterations in (pericellular) purinergic pathways: extracellular ATP, a proinflammatory danger signal, which activates the killing of Mtb in macrophages, is rapidly hydrolyzed to AMP by CD39, which is expressed by various regulatory cells (14). The degradation of ATP to AMP in the microenvironment was accompanied by a switch in macrophage gene expression from type 1 toward type 2 , and Mtb infection actively upregulated expression of the adenosine A2A receptor on macrophages (22). This receptor has been described as a major immunosuppressive immune cell adenosine receptor acting through elevation of cAMP (23), and its expression on macrophages was central to M2-like polarization after Mtb infection (22). Other cell types acting as APCs were demonstrated to contribute to Treg induction: both hepatitis $\mathrm{C}$ virus (HCV)infected hepatocytes and $H$. pylori-infected gastric epithelial cells directly induced Tregs through production of TGF- $\beta(24,25)$.

Regulatory T-cells can also be induced directly through pathogen-derived components. This has been demonstrated in several murine studies: zwitterionic capsular polysaccharides from S. pneumoniae induced $\mathrm{CD}^{+} \mathrm{CD} 28^{-}$Tregs that were CD $122^{\text {LO }}{ }^{\text {CTLA }}-4^{+}$CD $39^{+}$, synthesized IL-10 and TGF- $\beta$, and exhibited suppressive activity. This induction was independent 
of APCs and involved direct crosslinking of the TCR (26). In another murine study, proteins secreted by $H$. polygyrus induced Foxp $3^{+}$T-cells through ligation of the TGF- $\beta$-receptor (27). The herpes virus entry mediator HVEM, a binding site for viral glycoprotein $\mathrm{HSVgD}$, is upregulated on murine $\mathrm{CD} 4^{+} \mathrm{Foxp}^{+}$ Tregs after HSV-1 infection, and activation of this receptor led to preferential expansion of Tregs (28). In the human situation, $\mathrm{CD} 4{ }^{+} \mathrm{CD} 25^{+}$Tregs exhibited extended survival and increased suppressive capacity after binding HIVgp120 (29).

The preferential expression of TLRs, such as TLR2, on Tregs as compared to "conventional" T-cells has been reviewed by Sutmuller and colleagues (2). A large variety of TLR2 ligands have been described in bacteria, including Mtb (30). Mtb-induced TLR-signaling in APCs leads to inhibition of the MHC-II transactivator-gene CIITA, thereby decreasing expression of MHC-II and antigen presentation (30). During chronic Mtb infection, prolonged TLR2 signaling (e.g., through the $19 \mathrm{kD}$ lipoprotein) can lead to suppressive cytokine production (31) and recruitment of $\mathrm{CD}^{+}{ }^{+}$Tregs to the lung (32). A role for TLR-mediated Treg induction has also been described in murine malaria: murine Plasmodium-activated DCs induced Tregs through TLR9, and TLR $9^{(-/-)}$mice had impaired activation of Tregs, associated with a partial resistance to lethal infection (33). Other factors in the local environment vital for the expansion and function of Tregs include changes in metabolism (34), endothelial cytokine (IL-33) production and cytokine balance (IL23:IL-33 ratio) (35), and metabolite products from commensal microbiota $(36,37)$. Thus, specific pathogen components can skew toward Treg phenotype or function. The significance of these Tregs for the disease process, concomitant diseases, and vaccinations will be discussed further below.

\section{The Impact of Tregs in Infectious Diseases}

\section{Viral Infections: Acute vs. Chronic Infectious Disease}

Regulatory T-cells have been found after retrovirus-, RNA virus-, and DNA virus infection in mice and humans [reviewed in Ref. (3); Figure 1A]. Various $\mathrm{CD} 4^{+}$and $\mathrm{CD} 8^{+}$Treg subsets have been identified (38), but mostly in chronic viral infection. Yet, in hepatitis A virus infection - an acute inflammatory disease, usually followed by pathogen clearance - hepatitis A virus bound to its cellular receptor (HAVCR1), which is expressed on Tregs, which resulted in inhibited Treg function and inflammation (39). By contrast, in acute dengue fever, Treg function and the suppression of vasoactive cytokine release were similar in acutely infected and recovered patients, such that in this case, the disproportionate activation of pro-inflammatory cells and cytokines often found in dengue fever was not explained by acute phase Treg malfunction (40). Thus, blockade of Tregs in acute viral infection could assist in pathogen clearance, at the cost of temporary hyper-inflammation, but not all (pathological) hyper-inflammation is associated with Treg hypo-functionality. On the other side, Tregs could also benefit the host during acute infection: first, Treg depletion in murine herpes simplex infection increased LN levels of IFN- $\alpha$ and $-\gamma$, but infection-site-associated IFN $\gamma$ was decreased, and the arrival of DCs, NK cells, and T-cells at the infected lesion was delayed (41), pointing to a role for Tregs in promoting LN in- and efflux of pro-inflammatory cells (42). Second, Tregs may suppress infected cell proliferation at the mucosal point-of-entry to a level where infection cannot be established, which was suggested as a protective mechanism in early HIV infection $(43,44)$. Third, Tregs were vital in allowing memory formation through promoting antigen persistence, as was recently demonstrated in a murine West Nile virus infection model (45).

The role of human Tregs in chronic viral infection has been more extensively delineated. A meta-analysis of 12 studies demonstrated increased $\mathrm{CD}^{+}{ }^{+}$Treg frequencies in chronic hepatitis $B$ virus (HBV) infection compared to both acute infection and healthy controls, revealing a strong association of Tregs with disease progression, viral load, absence of therapy response, and risk of hepatocellular carcinoma (46). In chronic HCV infection, the contribution of Tregs to low inflammatory $\mathrm{CD} 4^{+}$and $\mathrm{CD} 8^{+}$ $\mathrm{T}$-cell responses has been described $(47,48)$. Tregs were recruited to the liver through the Treg-attracting chemokines CCL17 and CCL22 (49), thereby promoting pathogen persistence. It has been argued, however, that Tregs may also be functional in limiting $\mathrm{HCV}$-induced liver damage (48).

In chronic HIV infection, $\mathrm{CD} 4^{+}$Tregs were relatively increased in the mucosa and in the circulation compared to healthy controls, but the Treg-mediated effects on anti-HIV immune responses remain a matter of debate (50). $\mathrm{CD}^{+}{ }^{+}$Tregs decreased HIV replication in T-cells in vitro through CD39-mediated ectonucleotide shifts and by transfer of cAMP through gap junctions formed with conventional T-cells (43). Tregs inhibited spreading of virus from DCs to T-cells through interfering with the immunological synapse (51). In another study, blocking of CD39 by monoclonal antibodies (mAbs) restored cytokine production by HIV-gagstimulated $\mathrm{CD}^{+}{ }^{+} \mathrm{T}$-cells (52). Indeed, the relative frequency of $\mathrm{CD}^{+}{ }^{+} \mathrm{CD} 39^{+}$Tregs positively correlated with HIV viral load and disease progression in infected individuals (53). These different effects of Tregs could be explained by differentiating between acute and chronic infection, as argued in Ref. (50): control of viral replication by $\mathrm{CD}^{+}\left(\mathrm{CD} 39^{+}\right)$Tregs may be important early after infection with a limited number of infected cells (relatively high Treg: T-effector ratio), yet during chronic infection Tregs may not be able to suppress proliferation of all infected cells, and potentially become more detrimental due to dampening anti-HIV responses. This points to the need for more detailed analyses of Treg functions in acute vs. chronic (hyper-) inflammation.

\section{Bacterial Infections: Reservoirs for Treg Induction}

Early vs. late effects of Tregs in bacterial infection were elegantly described in a mouse model of Salmonella (Salmonella enterica serotype Typhimurium): Tregs suppressed early protective immunity, thereby allowing for establishment of infection, yet clearance of infection at later time points corresponded with a decrease in Treg suppressive capacity (54). After acute infection, Tregmediated failure to completely eradicate Salmonella may thus lead to a carrier state of persistent asymptomatic infection, resulting in a reservoir for shedding of pathogens into the environment and further infection [reviewed in Ref. (55)]. A carrier state of Streptococcus pneumonia in the nasopharynx was associated with increased TGF- $\beta$ levels from nasal washes in humans, and 


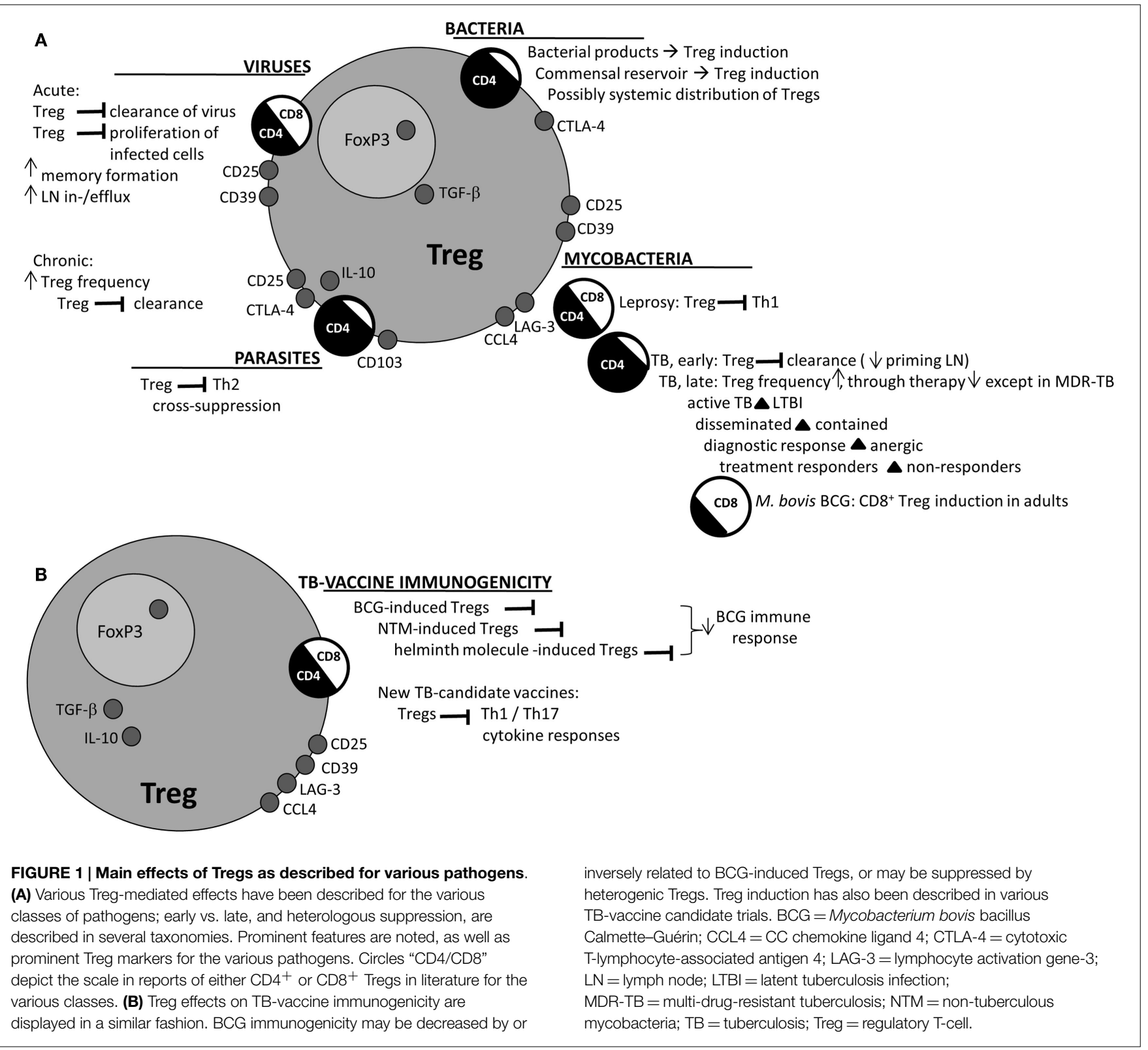

TGF- $\beta$ was shown to lead to Treg expansion in in vitro murine experiments (56). In Helicobacter pylori infection, a carrier state can last for life; and several studies have described the ability of Helicobacter pylori to induce Tregs. These Tregs were found in the circulation as well as in the gastric mucosa of both infected children and adults, and though Tregs initially can limit inflammation and therefore probably gastric ulceration, pathogen persistence could, on the other hand, lead to chronic inflammation and tumor induction (57) [reviewed in Ref. (58)].

Increasing attention has been drawn to the interplay of the immune system with non-pathogenic commensal microbiota in the intestine. Tregs can be induced by commensal microbiota, as has been demonstrated in multiple murine studies: butyrate, a metabolite from commensals, potently induced Tregs in the intestine $(36,37)$, possibly through butyrate-mediated enhanced histone $\mathrm{H} 3$ acetylation in the FOXP3 promoter (37). Polysaccharide
A (PSA) from $B$. fragilis induced conversion of T-cells into Tregs, and cured experimental colitis (59). The CNRZ327-component from Lactobacillus delbrueckii induced regulatory responses in colonic tissue, but importantly also in cecal LNs and the spleen, pointing to systemic distribution of these microbiota-induced Tregs (60).

Raising mice in germ-free conditions decreased the number of Tregs in the gut, but the number of cutaneous Tregs was increased, possibly through loss of inhibition by pro-inflammatory cells (61). In any case, data on activation of Tregs by skin commensals is also emerging (61), and these Tregs induced by skin microbiota may modulate systemic inflammatory responses (61). As recently reviewed (62), increasing evidence reveals resident microbiota in the lungs. Though relatively low in bacterial biomass compared to the microbiota of the skin and the intestinal mucosa, these microorganisms are present in healthy lungs as they are 
at other mucosal surfaces, and probably differ in composition between healthy individuals and individuals with (pulmonary) disease (62).

Clearly, mucosal surfaces are the primary sites both for pathogenic and commensal microbiota; and induction of Tregs within the myriad of innate and adaptive cells - has been described for both. Further research should elucidate local and systemic effects of Tregs induced at barrier sites in human studies, and whether systemic effects of Tregs induced by (non-pathogenic) commensals are to be expected (Figure 1A).

\section{Parasitic Infections: Suppression Across Boundaries}

Murine Leishmaniasis models have been pivotal in demonstrating Tregs at the site of (parasitic) infection: antigen-specific $\mathrm{CD} 4{ }^{+} \mathrm{CD} 25^{+}$Tregs were present at the site of chronic Leishmania major infection (63) and retention at the infection site was dependent on expression of $\mathrm{CD} 103$ by $\mathrm{CD} 4{ }^{+} \mathrm{CD} 25^{+}$Tregs (64). In this model, the impact of Tregs on establishment of chronic infection and reactivation of disease was elegantly demonstrated: after pathogen clearance, Leishmania super-infection led to reactivation of disease and increased Treg numbers at the primary site. Also, adoptive transfer of Tregs from infected mice into chronically infected mice caused reactivation of disease (65). Mechanisms of suppression included IL-10 production by Tregs as well as other mechanisms (66). In another study, Foxp3-negative cells were the major producers of IL-10, and anti-IL-10R mAb treatment decreased parasite burden to a greater extent compared to anti-CD25-mAb treatment (67). In humans, functionally suppressive $\mathrm{CD} 4{ }^{+} \mathrm{CD} 25^{+}$Tregs have been isolated from cutaneous leishmaniasis (skin) lesions (68); and FOXP3 mRNA levels in skin lesions were increased in chronic compared to acute Leishmania major infection (69). Also in Leishmania guyanensis-induced skin lesions, FOXP3 mRNA levels were significantly higher in chronic compared to acute patients, though in both cases Tregs isolated from these lesions displayed suppressive activity in vitro (70). Importantly, IL-10 and FOXP3 mRNA expression in Leishmania guyanensis-infected skin lesions were associated with unresponsiveness to treatment (71).

Several studies have reported increased Treg frequencies in Plasmodium falciparum-infected individuals compared to asymptomatic or uninfected controls (72); furthermore in patients with clinically severe malaria, the frequency of $\mathrm{CD} 4^{+} \mathrm{CD} 25^{+} \mathrm{Foxp}^{+} \mathrm{CD} 127^{\mathrm{LO}}$ Treg cells correlated with levels of parasitemia and total parasite biomass (73). Tregs were associated with risk of malaria disease: reduced expression of CTLA-4 and FOXP3 was found in Fulani, an ethnic group in Burkina Faso relatively resistant to $P$. falciparum compared to Mossi (a different ethnic group from the same region) (74). Proliferative PBMC responses to malaria antigens from Mossi were increased following $\mathrm{CD} 25^{+}$-depletion, but those from Fulani were not (74). In Kenyan adults with natural immunity to malaria, $\mathrm{CD} 4{ }^{+} \mathrm{CD} 25^{\mathrm{HI}}$ T-cell frequency at enrollment was associated with the risk of developing clinical malaria during follow-up (75).

Many helminth parasitic infections steer immunity toward Th2 and T-regulatory responses (12); and murine data indicate that immune suppression is achieved through cross-mucosal induction of regulatory cytokines, regulatory DCs, macrophages, and $\mathrm{CD}^{+}{ }^{+}$and $\mathrm{CD} 8{ }^{+}$Tregs (76). In a recent study of murine Trichuris muris infection, Th2 cell proliferation was enhanced by early Treg depletion post-infection and by Treg depletion after establishment of infection (77). However, the ultimate effect of Tregs on pathogen persistence was clearly time dependent: both early and late Treg depletion enhanced Th2 responses and reduced Th1 responses, but while early Treg depletion resulted in enhanced clearance of infection, later, during infection, Treg depletion resulted in enhanced worm burden (77).

Importantly, in geohelminth-infected children in vitro depletion of $\mathrm{CD} 4{ }^{+}$Foxp $^{+} \mathrm{CD} 25^{\mathrm{HI}}$ T-cells increased not only antigenspecific proliferative responses but also IFN $\gamma$-production in response to Plasmodium-infected red blood cells (11). The in vivo effect of helminth coinfection on immunity against Plasmodium varies between studies, but helminth coinfection may be associated with protection against cerebral malaria, a state of severe hyper-inflammation (12). Latent tuberculosis infection (LTBI) individuals with hookworm (78) and filarial coinfection (79) had decreased Th1 and Th17 responses and increased Treg frequencies compared to parasite-uninfected LTBI individuals. Whether deworming has clinical impact on the course of TB disease is not clear: in TB patients with helminth coinfection, albendazole treatment decreased IL-10 levels, but there was no clinical improvement in TB after 2 months (80). Since (helminth-induced) Tregs are capable of exerting non-specific suppressive responses, research in malaria and TB (diseases where strong Th2 and Th1 responses are vital, respectively) will hopefully clarify the effect of Tregs across the boundaries of disease (Figure 1A), especially in settings where coinfection of helminths with malaria and/or TB is endemic.

\section{Tregs in Leprosy and Tuberculosis}

\section{Tregs in Leprosy, an Ancient Disease}

Leprosy, caused by $M$. leprae, is an ancient, chronic, disabling, but curable disease affecting the skin, the peripheral nerves, the eyes, and mucosa of the respiratory tract (81). The clinical spectrum of the disease ranges from tuberculoid (TT) and borderline tuberculoid (BT) to borderline lepromatous (BL) and lepromatous leprosy (LL), where TT/BT is immunologically characterized by a strong Th1 response accompanied by limited growth of the bacillus (paucibacillary leprosy), whereas BL/LL is classically characterized by a predominant Treg/Th2 response, high antibody titers, absent granuloma formation, and thus poor containment of infection and clinical deterioration (82).

Though the exact mechanisms ruling this spectrum have not been elucidated, it is clear that Tregs play a part, and demonstration of the suppressive activity of $\mathrm{CD} 4^{+}$and $\mathrm{CD} 8^{+}$Tregs isolated from the skin and circulation of LL patients were among the first reports on "human T-suppressor cells" $(6,7)$. In the circulation of leprosy patients, both $\mathrm{CD}^{+}{ }^{+} \mathrm{Foxp}^{+}$and $\mathrm{CD} 8^{+} \mathrm{Foxp}^{+} \mathrm{T}$ cells were almost twofold increased compared to healthy contacts (83). Within the spectrum of disease, increased percentages of $\mathrm{CD}^{+}{ }^{+}$Foxp $3^{+} \mathrm{CD} 25^{+}$and $\mathrm{CD} 8^{+}$Foxp $^{+}{ }^{+} \mathrm{CD} 25^{+}$T-cells have been demonstrated in the circulation of LL patients compared 
to BT patients or healthy contacts $(82,84)$. Also in lepromatous lesions, Foxp $3^{+}$T-cells were increasingly expressed in LL compared to TT/BT patients $(82,84)$. Suppression of the Th1 response by Tregs was demonstrated by enhanced in vitro IFN $\gamma$ production through depletion of $\mathrm{CD} 25^{+}$cells in a subset of LL patients (82). Both $\mathrm{CD} 4^{+} \mathrm{CD} 25^{+}$derived IL-10 production and regulation through TGF- $\beta$ have been described $(85,86)$.

A possible mechanism of Treg induction by M. leprae-infected DCs is the expression of the mycobacterial cell wall component PGL-1, that by association with the complement component C3 can steer toward Treg differentiation (87). Type 2 antiinflammatory $\left(\mathrm{CD}_{163}{ }^{+}\right)$macrophages are important Treg inducers (17), possibly due to the action of ROS (88); indeed, a regulatory phenotype was described in monocytes stimulated with M. leprae (89). Recently, $\mathrm{CD} 68^{+} \mathrm{CD} 63^{+}$cells were demonstrated in LL skin lesions with increased frequencies compared to BT/TT lesions (82). Intracellular pathways leading to enhanced Foxp3 expression in $\mathrm{CD} 4{ }^{+}$T-cells have been described in association with progression of disease toward BL/LL, in addition to low Foxp3 ubiquitination (marked for intracellular degradation) (86). In T-cells isolated from LL patients, Foxp3 interacted with histone deacetylases and bound directly to the promotor regions of CD25 and CTLA-4 (90). The importance of this transcriptional regulation by Foxp 3 within the immunological spectrum of disease is further supported by the fact that not only Treg frequencies are increased in LL compared to BT patients but also the intensity of expression (mean fluorescence intensity) of Foxp3 as determined by flow cytometry (83).

Thus, Tregs are clearly involved in the impairment of mycobacterial control. However, this does not necessarily equate to increased suppression of Th1 over Th2 responses toward the LL pole spectrum: gene expression profiling of PBMCs isolated from TT, LL, and borderline leprosy patients revealed decreased expression of both Th1 and Th2 genes in LL patients, but enhanced expression of CTLA-4 and TGFB1 (91). The authors further found overexpression of CBL-B, an E3 ubiquitin-ligase that after encounter with antigen is crucial in modulating T-cells toward activation vs. anergy, dependent on the presence or absence of costimulatory signals (92). Cbl-b, TGF- $\beta$, and CTLA- 4 expression were molecularly related, as demonstrated by the dependency of Cbl-b expression on TGF- $\beta$ and the decreased expression of Cblb after treatment with CTLA-4 siRNA (91). Within the paradigm of a generalized suppressed peripheral T-cell response associated with LL development, Tregs could thus play an important role in inducing and maintaining low cellular immune responsiveness (Figure 1A), although their impact on humoral (mostly but not exclusively Th2 related) responses remains less clear. Further work would be needed to clarify causal relationships, e.g., if Tregs are a cause or consequence of bacterial burden in LL disease (93).

\section{Tuberculosis: Early and Late Effects of Tregs}

Pathogen-specific Tregs were induced by Mtb as demonstrated in a murine Mtb aerosol infection model, and these Tregs delayed priming of $\mathrm{CD}^{+}$and $\mathrm{CD} 8^{+}$T-cells in the pulmonary LNs, thereby delaying migration of these cells to the lung (94). Tregs were demonstrated in the lung, including in granulomas (95), and were shown to prevent pathogen clearance (96). Interestingly, in contrast to Listeria monocytogenes, pathogen-specific Treg expansion could be found in LNs only after Mtb infection (97). Thus, Mtb-induced Tregs contribute to the delayed onset of adaptive immunity that is observed in TB compared to other diseases and which allows establishment of infection $(98,99)$. The impact of Tregs on establishment of infection was further demonstrated in a murine study, where depletion of $\mathrm{CD} 25^{+}$cells early after Mtb infection - but not during chronic infection - decreased bacterial load and granuloma formation (100). However, it might also be that (pre-existing) Tregs have a beneficial role very early in infection, but also these data are only derived from animal experiments. In macaques, Tregs and IFN $\gamma$-producing effector T-cells expanded early after pulmonary TB infection, yet in vivo depletion of both IFN $\gamma$-producing and Tregs led to decreased resistance against granuloma progression (101). Analogous to the possibly beneficial role for Tregs in regulating LN in- and efflux during early murine HSV-infection $(41,42)$, it is conceivable that the presence of a very low level of (possibly pre-existing) Tregs before or in a very early state after Mtb infection might thus accommodate priming and subsequent emergence of a pro-inflammatory immune response. Clearly, further research will be needed to specify the impact of Tregs in various organs (102), early in (human) Mtb infection, and to differentiate their impact in early vs. chronic infection (Figure 1A).

Regulatory T-cells are also present in human Mtb infection as has been demonstrated extensively: Tregs could be isolated both from the circulation and from the site of infection in TB patients. In the circulation of TB patients, an increase in FOXP3 mRNA expression was found compared with healthy controls (103), and also an increase in $\mathrm{CD}^{+}$T-cell frequencies with regulatory phenotypes was demonstrated [defined as $\mathrm{CD} 4^{+} \mathrm{CD} 25^{+/ \mathrm{HI}}(103,104), \mathrm{CD} 4^{+} \mathrm{Foxp}^{+} \mathrm{CD} 25^{\mathrm{HI}}(105,106)$, or $\mathrm{CD} 4{ }^{+} \mathrm{CD} 25^{\mathrm{HI}} \mathrm{CD} 39^{+}$(105)]. Tregs could be isolated from various Mtb-infected sites, including bronco-alveolar lavage (BAL) fluid, ascites, pericardial fluid, and pleural fluid; and FOXP3 mRNA expression levels and $\mathrm{CD} 4{ }^{+} \mathrm{CD} 25^{\mathrm{HI}}$ T-cell frequencies were increased stronger locally than systemically (in the circulation) $(103,107)$. In a study comparing TB cases with infected and uninfected TB contacts (defined by positive tuberculin-skin test (TST) and ELISPOT results), PBMCs from uninfected contacts had lower FOXP3 mRNA expression levels compared to TB cases, but higher FOXP3 expression levels compared to infected TB contacts; which according to the authors could signify migration of Tregs to the lungs during early infection, with a reappearance in the circulation during latent (established) infection (108). Also $\mathrm{CD}^{+}{ }^{+}$Foxp $^{+}{ }^{+} \mathrm{CD} 25^{+}$Tregs were demonstrated in the circulation and BAL fluid of TB patients (107); and CD8 ${ }^{+} \mathrm{LAG}_{-} 3^{+} \mathrm{CCL} 4^{+}$ Tregs [lymphocyte activation gene-3 (LAG-3); CC chemokine ligand 4 (CCL4)] were shown by histological staining of infected LNs from TB patients (109). Furthermore, after stimulation with HLA-E restricted Mtb-derived peptides $\mathrm{CD}^{+}$Tregs could be isolated from PBMCs of in vitro mycobacterial purified protein derivative (PPD)-reactive donors $(110,111)$.

Elevated frequencies of circulating Tregs in TB patients declined during successful chemotherapy (106), in contrast, in patients with emerging MDR-TB circulating Treg frequencies remained persistently high (106). Other data on Tregs in MDR vs. 
normally resistant (NR)-TB are scarce and conflicting: similar frequencies of circulating $\mathrm{CD} 4^{+} \mathrm{Foxp}^{+}$Tregs were found in MDRTB patients compared to (NR-)TB patients (112); however, in another study comparing MDR-TB, NR-TB, and non-tuberculous mycobacteria (NTM) infections, increased ex vivo frequencies of Tregs were found in MDR-TB but also in NTM infections compared to NR-TB. This may reflect chronicity of infection in MDRTB and NTM infection, which is often treated sub-optimally; however, the contrast reported by the authors between elevated serum IL-10 levels in MDR-TB patients vs. elevated serum TGF$\beta$ levels in NTM-infected patients could also suggest different subsets of Tregs or different suppressive effector pathways to be involved in MDR-TB vs. NTM (113).

\section{Tuberculosis: Tregs Differentiate Active from Latent Disease}

$\mathrm{CD}^{+}{ }^{+}$Foxp $^{+}{ }^{+} \mathrm{CD} 25^{+}$Tregs are increased in frequency in active TB compared to LTBI $(107,114)$, both in the circulation and in BAL fluid (107) (Figure 1A). A report on CD4 ${ }^{+} \mathrm{CD} 25^{+} \mathrm{CD} 134^{+}$ T-cells in TB demonstrated differentiation between active and latent TB solely through the presence or absence of the CD39molecule on this subset (115). Stasis of mycobacterial growth in macrophages, both monocyte-derived and alveolar, was suppressed by CD $4{ }^{+}$Tregs (107). Depletion of CD $4^{+}$Foxp $3^{+} \mathrm{CD} 25^{\mathrm{HI}}$ T-cells increased IFN $\gamma$ responses to the mycobacterial antigen heparin-binding hemagglutinin (HBHA) of patients with active TB in vitro, to the level observed in LTBI individuals (116). Treg frequency in the circulation of smear-positive TB patients was increased compared to smear-negative patients; however, this did not correlate with radiologic determination of extent of disease (112).

Pro-inflammatory signatures of $\mathrm{CD}^{+}$T-cells differentiated between latent infection and active TB disease (117), and also in vitro an association was found between burden of infection of cells and lysis by cytotoxic CD8 ${ }^{+}$T-cells (118). The frequency of $\mathrm{CD}^{+}{ }^{+}$T-cells producing IL-10 or TGF- $\beta$ was increased in active TB patients compared to latently infected or control subjects (119). In this study, $\mathrm{CD}^{+}, \mathrm{CD}^{+} \mathrm{IFN}-\gamma^{+}$, and $\mathrm{CD} 8^{+} \mathrm{IL}-17^{+} \mathrm{T}-$ cell numbers were similar between groups, and were - interestingly - not dependent on sputum bacillary load, while sputum bacillary load was positively associated with specific regulatory cytokine expression in $\mathrm{CD}^{+}$T-cells, and negatively associated with $\mathrm{CD}^{+}$granzyme B expression (119). However, in another study, the frequency of $\mathrm{CD} 8^{+}$Foxp $3^{+} \mathrm{CD} 25^{+}$Tregs did not differ between active vs. latent TB, or between cells isolated from the circulation vs. cells isolated from BAL fluid (107). The differences between these reports may be explicated by differences in regulatory markers that were studied, or by methods that were used: in the former study, cells were stimulated with Mtb specific antigen for $96 \mathrm{~h}$, while in the latter study, cells were PPD-stimulated for $12 \mathrm{~h} \mathrm{CD}^{+}$Tregs are relatively understudied compared to CD ${ }^{+}$ Tregs in mycobacterial infection (5), and this clearly points to the need for more (uniform) research into these possibly important regulators and/or markers of activity of disease. Of note, $\mathrm{CD} 8^{+}$ Tregs were found at the disease site in mice, and progression of disease correlated with accumulation of IL-10-secreting CD8 ${ }^{+}$ T-cells in granulomas (120).
Instead of being a steady state of infection, latent TB comprises a dynamic spectrum with supposedly increasing rates of subclinical Mtb replication and inflammation extending eventually to active TB. Serial IGRA testing has been proposed as an indicator of human host resistance in latent TB. Using serial testing, a consistently negative test in TB-exposed individuals would likely indicate strong resistance to infection, a consistently positive test (recent) active infection, and (repeated) test conversions (positive to negative, possibly followed by conversion, etc.) changing dynamics of infection and control of bacterial load. In a comparison of T-cell subsets between IGRA-consistently positive and consistently negative TB-case contacts, $\mathrm{CD} 4^{+}{ }^{+}$Foxp $3^{+}$ and $\mathrm{CD} 4{ }^{+} \mathrm{CTLA}-4^{+}$Tregs were increased in TB-case contacts with consistently positive IGRA-tests, possibly indicating Treg interference with host resistance in the development of active infection (121).

\section{Tuberculosis: Tregs in Extra-Pulmonary Disease}

A minority of TB cases present with extra-pulmonary disease or extra-pulmonary involvement following pulmonary infection, and it is assumed that this represents failure of the immune system to contain infection (122). Multiple studies indicate involvement of Tregs in dissemination of disease (Figure 1A). An increase in FOXP3 mRNA expression has been described in PBMCs from patients with extra-pulmonary TB (disseminated and lymphatic $\mathrm{TB}$ ) compared to pulmonary TB (103). In a comparison of TB pleural effusion and miliary $\mathrm{TB}$, representing in this case containment vs. dissemination of disease, elevated FOXP3 mRNA expression levels and frequencies of $\mathrm{CD} 4{ }^{+}$Foxp $3^{+} \mathrm{CD} 25^{+} \mathrm{T}$-cells were found in cells isolated from miliary disease sites (123). Another study confirmed an increase in $\mathrm{CD} 4{ }^{+}$Treg frequencies in patients previously treated for extra-pulmonary TB compared to pulmonary TB, but reported an analogous increase in $\mathrm{CD} 4^{+}$activation markers (124). In TB pleurisy, $\mathrm{CD} 4^{+}$Foxp $3^{+} \mathrm{CD} 25^{\mathrm{HI}}$ Treg frequencies were increased in pleural fluid compared to the circulation $(125,126)$, and Tregs suppressed IFN $\gamma$-expression in $\mathrm{CD}^{+}$ and $\mathrm{CD}^{+}{ }^{+}$T-cells (126). Pleural CD39 ${ }^{+}$Tregs inhibited generation of Th17 cells, which could be reversed in vitro by antagonizing TGF- $\beta$ through the addition of latency-associated peptide (LAP) (127). Mtb infection of the pleurae favored Treg migration into the pleural exudate when compared to other causes of pleurisy: tuberculous pleural fluid, but not effusions from other bacterial origin, or transudates, had high concentrations of the chemoattractant CCL22, which is chemotactic for Treg migration in vitro, and an increase in $\mathrm{CD} 4{ }^{+} \mathrm{CD} 25^{\mathrm{HI}} \mathrm{T}$-cell frequency compared to the circulation (125). Intercellular adhesion molecule-1 (ICAM1) and vascular cell adhesion molecule-1 (VCAM-1) on pleural mesothelial cells regulated migration of leukocytes from the circulation into the pleural fluid; however, these molecules also seemed to favor (non-antigen-specific) expansion of Tregs (128).

In TB lymphadenitis in children, $\mathrm{CD} 4^{+} \mathrm{Foxp}^{+} \mathrm{T}$-cells were demonstrated in the LNs, and quantitative mRNA analysis demonstrated induction of TGF $\beta$ and IL13, but not of IFN $\gamma$, TNF $\alpha$, or IL-17 (129). Data on frequency and function of Tregs in other forms of TB disease, such as bone TB, urogenital TB, or TB of the central nervous system (CNS) are scarce. It is, however, conceivable that the interplay of Tregs and Mtb may 
differ in infections at immune-privileged sites, such as the CNS or the eye. The assessment of anti-inflammatory mechanisms could be highly relevant in regard to CNS-immune reconstitution syndromes, given their often disastrous outcomes (130). Several studies have associated plasma biomarkers and $\mathrm{CD} 4^{+} \mathrm{T}$ cell activation with the development of HIV-associated immune reconstitution inflammatory syndromes (IRIS), but did not find an association with $\left(\mathrm{CD}^{+}\right)$Treg frequencies, both in the development of cryptococcal-IRIS disease (131) and TB-IRIS disease (131, 132). TB-IRIS may either be "unmasking" (of an occult infection) or "paradoxical" (worsening of a known infection during retroviral treatment) hyper-inflammation: decreased serum IL-10 levels were found in paradoxical compared to unmasking syndromes (133). Interestingly, this might represent Treg function, not Treg phenotype: a study in patients developing symptoms of Mycobacterium avium and intracellulare complex-infection, following commencement of retroviral treatment, reported a significant expansion of $\mathrm{CD} 4{ }^{+} \mathrm{Foxp}^{+} \mathrm{CD} 25^{+} \mathrm{CD} 127^{\mathrm{LO}}$ Tregs, but reduced functional capacity and diminished IL-10 secretion of these cells in in vitro suppression assays (134).

\section{Tuberculosis: Tregs in the Clinic}

Tregs may interfere with clinical diagnosis of TB (Figure 1A). Classically, diagnosing TB has relied for decades on the TST, testing cell-mediated immunity against intradermally injected Mtbderived tuberculin PPD. Skin anergy is defined as the absence of dermal reactivity in otherwise confirmed Mtb infection. In vitro PPD stimulation of cells isolated from PPD-reactive TB patients induced both IL-10 and IFN $\gamma$-production; however, cells from anergic TB patients produced only IL-10 but not IFN $\gamma$ (135). Reduced levels of IFN $\gamma$ and IL-2, and increased levels of IL-10 in anergic compared to PPD-reactive TB patients were confirmed in another study. This anergy was found only after in vitro stimulation with PPD - but not unrelated antigens, indicating an antigen-specific anergic reaction (136). Suppression of IL-2- and TNF $\alpha$-production was accompanied by $\mathrm{CD} 8^{+}$T-cell expansion and high levels of IL-10 in anergic TB patients, and CD8 ${ }^{+}$T-cell depletion and blocking of IL-10 reversed this suppression (137).

A direct effect of Treg-mediated suppression on interferon- $\gamma$ release assays (IGRAs), such as the in-tube QuantiFERON Test, has so far not been established. Nevertheless, several studies have described "rescue" of mycobacterial-specific IFN $\gamma$ production by Treg depletion in Mtb-infected individuals (104, 105, 114, 138). Interestingly, depletion of $\mathrm{CD}_{2} 5^{+} \mathrm{T}$-cells increased IFN $\gamma$ production by PBMCs in Mtb-infected individuals, but did not increase the production of IL-17A (114). Yet, pleural CD39 ${ }^{+}$ Tregs $\left(\mathrm{CD} 4{ }^{+} \mathrm{CD} 25^{+} \mathrm{CD} 39^{+} \mathrm{CD} 127^{-}\right)$inhibited Th17 differentiation (127), and an inverse correlation between production of IL-17A and CD39-expressing Tregs has been described after vaccination $(139,140)$. CD39 expression on Tregs may thus be more closely linked to suppression of IL-17 production compared to cells expressing CD25, but this needs further clarification. Also the extent of TB infection as determined by chest X-ray (CXR) scoring was associated with T-cell modulation: in a study dividing patients by severity of disease by CXR, double-negative (DN, $\mathrm{CD} 4^{-} \mathrm{CD}^{-}$) $\mathrm{TCR} \gamma \delta$ T-cells from patients with severe disease displayed a modulatory profile with high IL-10 production, in contrast to patients with less severe disease, where TCR $\gamma \delta \mathrm{DN}$ $\mathrm{T}$-cells displayed a pro-inflammatory cytokine profile with high IFN $\gamma(141)$.

During TB therapy, circulating $\mathrm{CD}^{+}$Treg frequencies declined as mentioned; however, this was only noted following chemotherapy for pulmonary TB (Figure 1A) (106, 142, 143). In contrast, an increase was noted during extra-pulmonary $\mathrm{TB}$ treatment $(143,144)$. Differences between forms of disease possibly represent differences in compartmentalization of Tregs, or heterogeneous kinetics of Treg contraction following decrease of bacterial burden. TB patients in which MDR-TB emerged during therapy had persistent circulating Treg frequencies (106), which could be analogous to a phenomenon observed during IFN $\alpha$ therapy for chronic HBV infection: therapy non-responders were characterized by an increase in $\mathrm{CD} 4{ }^{+} \mathrm{CD} 25^{+}$T-cells and IL-10producing cells (145). Thus, circulating Treg frequencies might be used as parameter of therapy response in specific states of TB disease.

\section{Tregs in Vaccination Against Tuberculosis}

Even in early life, immunoregulatory mechanisms, including Tregs, may dampen vaccine-induced immunity (146). We describe here how immunogenicity of TB vaccines may be influenced by Tregs, induced by the vaccination itself, by closely related pathogens, or induced by unrelated pathogens (Figure 1B). $M$. bovis BCG, the only available vaccine against TB, is a live bacterial vaccine aimed at inducing effective $T$-cell responses, yet BCG itself also induces Tregs (5). This ability to induce Tregs could limit its ability to induce optimal protective immunity against TB; it is, however, conceivable that future medicine may be able to tailor BCG-induced Tregs to regulate hyperinflammation.

\section{Tregs Induced by Vaccination: M. bovis Bacillus Calmette-Guérin}

Bacillus Calmette-Guérin, the only licensed vaccine against TB since 1921, was derived from virulent $M$. bovis by years of continuous in vitro passage. Estimates are that BCG has been given $>3$ billion times since its introduction, and it is part of the WHO Expanded Program for Immunization (EPI). BCG was used in one of the first experiments establishing the idea of "suppressor cells" interfering with control of infection: transfer of thymocytes from BCG-immunized rats suppressed immune responses in naïve recipient rats against new BCG infection (147). Though BCGvaccination induces $\mathrm{CD}^{+}{ }^{+}$and $\mathrm{CD}^{+}$effector $\mathrm{T}$-cell responses in newborns $(148,149)$ and protects them from disseminated forms of disease, it does not induce consistent protection against pulmonary $\mathrm{TB}$, especially in adults (150). We have previously hypothesized that one explanation for this lack of protection is the induction of Tregs by the vaccine among various other hypotheses (5). In a large cohort of 5675 South-African infants who had been vaccinated at birth, stimulation of whole blood with mycobacterial antigens at 10 weeks of age resulted in production of IFN $\gamma$ or IL-10, but not both (151). CD $4^{+} \mathrm{CD} 25^{+}$Treg cells were demonstrated in another study in BCG-vaccinated infants, and depletion of these Treg cells resulted in lower IL-10 levels in PPD-stimulated cell cultures (152). IL-10-producing $\mathrm{CD}^{+}{ }^{+} \mathrm{T}$-cells have been demonstrated in previously BCG-vaccinated adult donors, and in vitro 
suppression of target cell proliferation could be reversed by a blocking $\alpha$ IL-10-antibody (153).

$\mathrm{CD}^{+}$Tregs are generally less studied compared to $\mathrm{CD} 4^{+}$ Tregs, especially in infectious diseases (5). We have previously studied the presence, phenotype, and suppressive activity of $\mathrm{CD}^{+}$Treg cells among live BCG-stimulated PBMCs of in vitro PPD-responsive donors. Surprisingly, we found a significantly higher expression of regulatory markers on live (but not killed) BCG-activated $\mathrm{CD}^{+}{ }^{+}$T-cells compared to $\mathrm{CD} 4^{+}$T-cells, and there was significant enrichment of $\mathrm{CD}^{+}$Treg cells within the BCG-activated CD25 ${ }^{+}$T-cell compartment (154). Also, suppressive activity was dominantly present in live BCG-activated $\mathrm{CD} 8^{+}$, but not in live BCG-activated CD4 ${ }^{+}$T-cells (154). CD8 ${ }^{+}$Treg cells isolated from live BCG-stimulated PBMCs were enriched for expression of LAG-3 and CCL4, co-expressed CD25 and Foxp3, and inhibited Th1 cell proliferation (109). Inhibition was partly mediated by secretion of CCL4, which reduced $\mathrm{Ca}^{2+}$-influx early after TCR triggering (109). We have additionally described expression of CD39 on live BCG-activated CD8 ${ }^{+}$Treg cells, and a direct involvement of CD39 in mediating suppression by $\mathrm{CD} 8{ }^{+}$Tregs, as both the chemical CD39 antagonist ARL 67156 and a blocking $\alpha \mathrm{CD} 39$-antibody were able to partly inhibit the suppressive activity of $\mathrm{CD} 8^{+} \mathrm{CD} 39^{+}$Tregs (155). Of note, $\mathrm{CD} 8^{+}$Tregs could only be demonstrated in donors primed in vivo with mycobacteria, indicating a memory recall response following in vitro BCG stimulation. Taken together, our work identified at least two different mechanisms by which BCG-activated $\mathrm{CD} 8^{+}$Tregs could inhibit Th1 responses, via CCL4 and via CD39. Despite the above findings and despite the fact that CD8 was originally identified as a marker of Treg cells, then coined T-suppressor cells, pathogen-activated $\mathrm{CD}^{+}$Tregs still remain significantly understudied compared to $\mathrm{CD}^{+}{ }^{+}$Tregs. It is important to note here that in vitro stimulation with live BCG preferentially activated $\mathrm{CD}^{+}$Tregs (154), while stimulation with killed BCG (or PPD) seems to activate different populations.

\section{Tregs Induced by New TB-Candidate Vaccines}

Regulatory T-cell induction has been demonstrated in several TB-vaccine candidate trials. After M72/AS01-vaccination of South-African healthy adults, Tregs expanded concurrently with cytokine-producing pro-inflammatory CD4 ${ }^{+}$T-cells (156). Circulating $\mathrm{CD} 4{ }^{+} \mathrm{CD} 25^{+}$Foxp $3^{+}$T-cells were demonstrated after vaccination with another TB-vaccine candidate, modified vaccinia Ankara-85A (MVA85A). Interestingly, $\mathrm{CD} 4^{+} \mathrm{CD} 25^{+}$Foxp $3^{+}$T-cells were increased in recipients with low antigen 85A-specific IFN $\gamma$-responses compared to high IFN $\gamma$ responders (157). Also, the frequency of $\mathrm{CD} 4{ }^{+} \mathrm{CD} 25^{+} \mathrm{CD} 39^{+}$ T-cells was inversely related to IL-17A production in vitro (139). IL2RA mRNA expression on the day of vaccination and CTLA-4 expression 2 days after vaccination inversely correlated with the magnitude of the IFN $\gamma$ ELISPOT response induced by MVA85A vaccination in healthy British adults, pointing to a possible role for Tregs very early or even before vaccination (157). In African infants vaccinated with MVA85A, an early and strong innate response was associated with enhanced IFN $\gamma$ ELISPOT responses; thus, the authors concluded that Treg modulation of vaccine responses could differ between populations, and that more research is needed to explain these differences and the impact on vaccine efficacy (158). Assessment should, however, include possible dissimilarities between long-term effects of Tregs and early after vaccination.

\section{Other Tregs can Modulate TB-Vaccine-Induced Responses}

Regulatory T-cells induced by other microbes can likely alter immunogenicity of TB vaccines. Exposure to environmental mycobacteria may decrease TB-vaccine efficacy through crossreaction of antigens (94). Pre-existing immune responses can either "block" or "mask" the BCG-induced immune response, possibly explaining the decreased vaccine efficacy of BCG in developing countries, where there is a higher prevalence of environmental mycobacteria (159). Another potential explanation for decreased vaccine efficacy is induction of Tregs by environmental mycobacteria (160). Priming mice with $M$. chelonae before BCG-vaccination increased Foxp3 expression on BCGspecific $\mathrm{CD} 4{ }^{+} \mathrm{CD} 25^{+}$T-cells compared to non-sensitized mice, and $\mathrm{CD} 4{ }^{+} \mathrm{CD} 25^{+}$T-cells of sensitized mice decreased immune responses in vitro (161). Adoptive transfer of $\mathrm{CD}^{+} \mathrm{CD} 25^{+} \mathrm{T}$ cells into naïve mice suppressed IL-2-production in the lungs, and enhanced IL-10 after BCG-vaccination (161). Suppression after murine sensitization was reversed by a blocking $\alpha \mathrm{CD} 25-\mathrm{mAb}$ during challenge, indicating active involvement of cross-reactive Tregs during vaccination (162).

Modulation of DC TLRs by helminth molecules lead to increased Th2 and Treg responses, which possibly decreases vaccine efficacy in developing countries, where also the majority of the one billion helminth-infected people live (12). Tregs induced by helminths in mucosa-associated lymphoid tissue (MALT) may migrate to other sites, exerting nonspecific suppressive effects and preventing clearance of $\mathrm{Mtb}$ at distant sites as well (163). Although the frequency of $\mathrm{CD} 4^{+}$Foxp $^{+} \mathrm{CD} 25^{\mathrm{HI}}$ T-cells was similar in helminth-infected and non-infected Indonesian children, BCG-specific (and as mentioned, also Plasmodium falciparum-specific) proliferative responses were increased after depletion of $\mathrm{CD} 4{ }^{+} \mathrm{CD} 25^{\mathrm{HI}} \mathrm{T}$ cells in helminth-infected children only, pointing to differences in suppressive capacity induced by helminth infection (11). Deworming increased BCG immunogenicity in vivo and was accompanied by changes in TGF- $\beta$, but notably not by changes in Th2 cytokines (164).

\section{Modulating the Modulators: Future Prospects for Tregs in TB-Vaccination}

The ability of BCG to induce Tregs may in the future be exploited to benefit the human host in the contexts of auto-immune and/or hyper-inflammation-related diseases. This has been noted in a murine model of Parkinson's disease, where protection against nerve damage was induced by BCG-vaccination through Tregs (165). Also in experimental auto-immune encephalomyelitis, myelin oligodendrocyte glycoprotein-specific IFN $\gamma$-producing $\mathrm{CD} 4{ }^{+} \mathrm{T}$-cells, and both specific and non-specific $\mathrm{CD} 4^{+} \mathrm{IL}-17^{+} \mathrm{T}-$ cells in the CNS, were suppressed by cerebral BCG infection (166). Other murine studies have demonstrated BCG-induced suppression of asthma responses and dampening of colitis $(167,168)$. 
Further research will hopefully elucidate if and how these findings can be translated to the human situation.

Interestingly, mucosal vaccination of macaques with a vaccine consisting of inactivated simian immunodeficiency virus (SIV) and a live bacterial adjuvant (BCG or Lactobacillus) generated HLA-E restricted, non-cytolytic $\mathrm{CD}^{+}$Tregs (169). After challenge with SIV infection, these $\mathrm{CD}^{+}$Tregs suppressed proliferation of infected $\mathrm{CD} 4{ }^{+}$T-cells, thereby protecting almost all vaccinated macaques for up to 4 years after vaccination (169). As mentioned, in acute viral infection, Tregs could have a beneficial role to play, such as in acute SIV/HIV infection where Tregs decrease proliferation of infected cells at mucosal surfaces (44).

In a TB-vaccination context, however, it may be crucial to avoid excessive Treg induction by the vaccine. Analogous to the reduced burden of $\mathrm{TB}$ observed in mice following treatment with chemical compounds inhibiting Treg and Th2 induction prior to infection (170), a similar approach was tested in murine BCG-vaccination: chemical inhibition of Treg induction increased BCG-mediated protection against pulmonary TB in mice and favored central-memory T-cell induction (long-lived vaccine responses) (171). Blocking the IL-10-receptor with an $\alpha$ IL-10-receptor antibody increased BCG-induced Th1, Th17, innate lymphoid IFN $\gamma$, and IL-17 responses in mice, leading to enhanced protection against TB (172). An additional, important role for IL-22 producing NK cells through lysing of CD $4^{+}$Tregs was described, and addition of IL-22 also increased Th1 vaccineinduced responses (173). In contrast, only moderate efficacy of treatment with a blocking $\alpha \mathrm{CD} 25$-antibody on BCG-vaccine efficacy was described (174). It is possible that blocking CD25 results in partial Treg depletion while other Treg subsets could survive during such treatment. However, CD25 is expressed also by activated T-helper cells such that CD25-depletion may additionally also deplete essential effector cells of protective immunity. Regardless, even after selective deletion of all Foxp $3^{+}$cells, homeostatic expansion may occur from a small subset of remaining Tregs (175). Since various Treg marker-expressing subsets exist, this points to the importance of assessing the dynamics and fluidity of various subsets within the Treg compartment, in order to improve vaccine design by effective modulation of Treg activity and function. Compounds inhibiting Treg induction or blocking "upstream" signaling through the IL-10-receptor could improve vaccine efficacy. Other options would include the addition of adjuvant antagonists of chemokine receptors expressed by Tregs, as described for a CCR4 antagonist that blocked CD4 ${ }^{+}$Tregs and increased in vitro responses to MVA85A and recombinant HBV surface antigen vaccination (176), or the inclusion of TLRagonists combined with agents selectively blocking TLR-induced

\section{References}

1. Belkaid Y, Tarbell K. Regulatory T cells in the control of host-microorganism interactions. Annu Rev Immunol (2009) 27:551-89. doi:10.1146/annurev. immunol.021908.132723

2. Sutmuller RP, Morgan ME, Netea MG, Grauer O, Adema GJ. Toll-like receptors on regulatory $\mathrm{T}$ cells: expanding immune regulation. Trends Immunol (2006) 27:387-93. doi:10.1016/j.it.2006.06.005 anti-inflammatory signaling pathways in DCs (177). Future studies may integrate these findings to increase TB-vaccine-induced protective immunity through manipulation of the manipulators, and hopefully translate these findings ultimately to the human situation.

\section{Concluding Remarks and Future Directions}

For many pathogens, induction, expansion, recruitment, or inhibition of Tregs has been demonstrated. Mycobacterium leprae and Mycobacterium tuberculosis are master manipulators of human immunity and are able to establish chronic infection among others by activating immune regulation. The effects of Tregs impact on clinical symptoms and performance of immunodiagnostic assays, differ in acute vs. chronic diseases and can suppress protective immunity and vaccine immunogenicity. Importantly, this can partly be the result of cross-suppression from Tregs induced by unrelated pathogens, possibly even by non-pathogenic microbes. This is particularly important in endemic settings, e.g., settings endemic for both helminths, TB, malaria, and HIV.

Through precisely (and timely) targeted Treg manipulation, vaccine-induced protective immunity may be enhanced. Most data are necessarily derived from murine studies, and need to be translated to the human situation. This should also offer opportunities for new immunotherapeutic vaccines for the treatment of inflammatory disorders, e.g., auto-immune diseases, and for the design of vaccines aimed at interfering with acute (viral) infection. Through manipulating the manipulators, increased immunity against infectious diseases may be achieved.

\section{Author Contributions}

All authors fulfill the criteria for authorship.

\section{Acknowledgments}

We acknowledge EC FP7 NEWTBVAC (contract no. HEALTH.F3.2009 241745), EC FP7 ADITEC (contract no. HEALTH.2011.1.4-4 280873), EC FP7 IDEA (Grant agreement no. 241642), and TBVAC2020 Horizon 2020 (contract no. 643381) (the text represents the authors' views and does not necessarily represent a position of the Commission who will not be liable for the use made of such information), The Netherlands Organization for Scientific Research (VENI grant 916.86.115), the Gisela Thier Foundation of the Leiden University Medical Center, and the Netherlands Leprosy Foundation. The funders had no role in study design, data collection and analysis, decision to publish, or preparation of the manuscript.

3. Maizels RM, Smith KA. Regulatory T cells in infection. Adv Immunol (2011) 112:73-136. doi:10.1016/B978-0-12-387827-4.00003-6

4. Abbas AK, Benoist C, Bluestone JA, Campbell DJ, Ghosh S, Hori S, et al. Regulatory T cells: recommendations to simplify the nomenclature. Nat Immunol (2013) 14:307-8. doi:10.1038/ni.2554

5. Joosten SA, Ottenhoff TH. Human CD4 and CD8 regulatory T cells in infectious diseases and vaccination. Hum Immunol (2008) 69:760-70. doi:10.1016/ j.humimm.2008.07.017 
6. Ottenhoff TH, Elferink DG, Klatser PR, de Vries RR. Cloned suppressor T cells from a lepromatous leprosy patient suppress Mycobacterium leprae reactive helper T cells. Nature (1986) 322:462-4. doi:10.1038/322462a0

7. Modlin RL, Kato H, Mehra V, Nelson EE, Fan XD, Rea TH, et al. Genetically restricted suppressor T-cell clones derived from lepromatous leprosy lesions. Nature (1986) 322:459-61. doi:10.1038/322459a0

8. Kapp JA, Bucy RP. CD8+ suppressor T cells resurrected. Hum Immunol (2008) 69:715-20. doi:10.1016/j.humimm.2008.07.018

9. Wing JB, Sakaguchi S. Multiple treg suppressive modules and their adaptability. Front Immunol (2012) 3:178. doi:10.3389/fimmu.2012.00178

10. Vignali DA, Collison LW, Workman CJ. How regulatory T cells work. Nat Rev Immunol (2008) 8:523-32. doi:10.1038/nri2343

11. Wammes LJ, Hamid F, Wiria AE, de Gier B, Sartono E, Maizels RM, et al. Regulatory $\mathrm{T}$ cells in human geohelminth infection suppress immune responses to BCG and Plasmodium falciparum. Eur J Immunol (2010) 40:437-42. doi:10. 1002/eji.200939699

12. van Riet E, Hartgers FC, Yazdanbakhsh M. Chronic helminth infections induce immunomodulation: consequences and mechanisms. Immunobiology (2007) 212:475-90. doi:10.1016/j.imbio.2007.03.009

13. Qureshi OS, Zheng Y, Nakamura K, Attridge K, Manzotti C, Schmidt EM, et al. Trans-endocytosis of CD80 and CD86: a molecular basis for the cell-extrinsic function of CTLA-4. Science (2011) 332:600-3. doi:10.1126/science.1202947

14. Dwyer KM, Deaglio S, Gao W, Friedman D, Strom TB, Robson SC. CD39 and control of cellular immune responses. Purinergic Signal (2007) 3:171-80. doi:10.1007/s11302-006-9050-y

15. Murray PJ, Wynn TA. Protective and pathogenic functions of macrophage subsets. Nat Rev Immunol (2011) 11:723-37. doi:10.1038/nri3073

16. Verreck FA, de Boer T, Langenberg DM, Hoeve MA, Kramer M, Vaisberg E, et al. Human IL-23-producing type 1 macrophages promote but IL-10producing type 2 macrophages subvert immunity to (myco)bacteria. Proc Natl Acad Sci U S A (2004) 101:4560-5. doi:10.1073/pnas.0400983101

17. Savage ND, de Boer T, Walburg KV, Joosten SA, van MK, Geluk A, et al. Human anti-inflammatory macrophages induce Foxp3+ GITR+ CD25+ regulatory T cells, which suppress via membrane-bound TGFbeta-1. J Immunol (2008) 181:2220-6. doi:10.4049/jimmunol.181.3.2220

18. Gupta N, Hegde P, Lecerf M, Nain M, Kaur M, Kalia M, et al. Japanese encephalitis virus expands regulatory $\mathrm{T}$ cells by increasing the expression of PD-L1 on dendritic cells. Eur J Immunol (2014) 44:1363-74. doi:10.1002/eji. 201343701

19. Trinath J, Maddur MS, Kaveri SV, Balaji KN, Bayry J. Mycobacterium tuberculosis promotes regulatory T-cell expansion via induction of programmed death-1 ligand 1 (PD-L1, CD274) on dendritic cells. J Infect Dis (2012) 205:694-6. doi:10.1093/infdis/jir820

20. Periasamy S, Dhiman R, Barnes PF, Paidipally P, Tvinnereim A, Bandaru A, et al. Programmed death 1 and cytokine inducible SH2-containing protein dependent expansion of regulatory T cells upon stimulation with Mycobacterium tuberculosis. J Infect Dis (2011) 203:1256-63. doi:10.1093/infdis/jir011

21. Siddiqui KF, Amir M, Gurram RK, Khan N, Arora A, Rajagopal K, et al. Latency-associated protein Acrl impairs dendritic cell maturation and functionality: a possible mechanism of immune evasion by Mycobacterium tuberculosis. J Infect Dis (2014) 209:1436-45. doi:10.1093/infdis/jit595

22. Dubois-Colas N, Petit-Jentreau L, Barreiro LB, Durand S, Soubigou G, Lecointe $\mathrm{C}$, et al. Extracellular adenosine triphosphate affects the response of human macrophages infected with Mycobacterium tuberculosis. J Infect Dis (2014) 210:824-33. doi:10.1093/infdis/jiu135

23. Ohta A, Sitkovsky M. Role of G-protein-coupled adenosine receptors in downregulation of inflammation and protection from tissue damage. Nature (2001) 414:916-20. doi:10.1038/414916a

24. Hall CH, Kassel R, Tacke RS, Hahn YS. HCV+ hepatocytes induce human regulatory CD4+ T cells through the production of TGF-beta. PLoS One (2010) 5:e12154. doi:10.1371/journal.pone.0012154

25. Beswick EJ, Pinchuk IV, Earley RB, Schmitt DA, Reyes VE. Role of gastric epithelial cell-derived transforming growth factor beta in reduced CD4+ T cell proliferation and development of regulatory T cells during Helicobacter pylori infection. Infect Immun (2011) 79:2737-45. doi:10.1128/IAI.01146-10

26. Mertens J, Fabri M, Zingarelli A, Kubacki T, Meemboor S, Groneck L, et al. Streptococcus pneumoniae serotype 1 capsular polysaccharide induces CD8CD28 regulatory T lymphocytes by TCR crosslinking. PLoS Pathog (2009) 5:e1000596. doi:10.1371/journal.ppat.1000596
27. Grainger JR, Smith KA, Hewitson JP, McSorley HJ, Harcus Y, Filbey KJ, et al. Helminth secretions induce de novo $\mathrm{T}$ cell Foxp3 expression and regulatory function through the TGF-beta pathway. J Exp Med (2010) 207:2331-41. doi:10.1084/jem.20101074

28. Sharma S, Rajasagi NK, Veiga-Parga T, Rouse BT. Herpes virus entry mediator (HVEM) modulates proliferation and activation of regulatory $\mathrm{T}$ cells following HSV-1 infection. Microbes Infect (2014) 16:648-60. doi:10.1016/j.micinf.2014. 06.005

29. Ji J, Cloyd MW. HIV-1 binding to CD4 on CD4+CD25+ regulatory T cells enhances their suppressive function and induces them to home to, and accumulate in, peripheral and mucosal lymphoid tissues: an additional mechanism of immunosuppression. Int Immunol (2009) 21:283-94. doi:10.1093/intimm/ dxn146

30. Harding CV, Boom WH. Regulation of antigen presentation by Mycobacterium tuberculosis: a role for Toll-like receptors. Nat Rev Microbiol (2010) 8:296-307. doi:10.1038/nrmicro2321

31. Saraav I, Singh S, Sharma S. Outcome of Mycobacterium tuberculosis and tolllike receptor interaction: immune response or immune evasion? Immunol Cell Biol (2014) 92:741-6. doi:10.1038/icb.2014.52

32. McBride A, Konowich J, Salgame P. Host defense and recruitment of Foxp3(+) $T$ regulatory cells to the lungs in chronic Mycobacterium tuberculosis infection requires toll-like receptor 2. PLoS Pathog (2013) 9:e1003397. doi:10.1371/ journal.ppat.1003397

33. Hisaeda $\mathrm{H}$, Tetsutani $\mathrm{K}$, Imai $\mathrm{T}$, Moriya $\mathrm{C}$, Tu L, Hamano $\mathrm{S}$, et al. Malaria parasites require TLR9 signaling for immune evasion by activating regulatory T cells. J Immunol (2008) 180:2496-503. doi:10.4049/jimmunol. 180.4.2496

34. O'Neill LA, Hardie DG. Metabolism of inflammation limited by AMPK and pseudo-starvation. Nature (2013) 493:346-55. doi:10.1038/nature11862

35. Schiering C, Krausgruber T, Chomka A, Frohlich A, Adelmann K, Wohlfert EA, et al. The alarmin IL-33 promotes regulatory T-cell function in the intestine. Nature (2014) 513:564-8. doi:10.1038/nature13577

36. Arpaia N, Campbell C, Fan X, Dikiy S, van der V, deRoos P, et al. Metabolites produced by commensal bacteria promote peripheral regulatory T-cell generation. Nature (2013) 504:451-5. doi:10.1038/nature12726

37. Furusawa Y, Obata Y, Fukuda S, Endo TA, Nakato G, Takahashi D, et al. Commensal microbe-derived butyrate induces the differentiation of colonic regulatory T cells. Nature (2013) 504:446-50. doi:10.1038/nature12721

38. Veiga-Parga T, Sehrawat S, Rouse BT. Role of regulatory T cells during virus infection. Immunol Rev (2013) 255:182-96. doi:10.1111/imr.12085

39. Manangeeswaran M, Jacques J, Tami C, Konduru K, Amharref N, Perrella $\mathrm{O}$, et al. Binding of hepatitis A virus to its cellular receptor 1 inhibits Tregulatory cell functions in humans. Gastroenterology (2012) 142:1516-25. doi:10.1053/j.gastro.2012.02.039

40. Luhn K, Simmons CP, Moran E, Dung NT, Chau TN, Quyen NT, et al. Increased frequencies of $\mathrm{CD} 4+\mathrm{CD} 25$ (high) regulatory $\mathrm{T}$ cells in acute dengue infection. J Exp Med (2007) 204:979-85. doi:10.1084/jem.20061381

41. Lund JM, Hsing L, Pham TT, Rudensky AY. Coordination of early protective immunity to viral infection by regulatory T cells. Science (2008) 320:1220-4. doi:10.1126/science.1155209

42. Kassiotis G, O'Garra A. Immunology. Immunity benefits from a little suppression. Science (2008) 320:1168-9. doi:10.1126/science.1159090

43. Moreno-Fernandez ME, Rueda CM, Rusie LK, Chougnet CA. Regulatory T cells control HIV replication in activated T cells through a cAMP-dependent mechanism. Blood (2011) 117:5372-80. doi:10.1182/blood-2010-12-323162

44. Haase AT. Perils at mucosal front lines for HIV and SIV and their hosts. Nat Rev Immunol (2005) 5:783-92. doi:10.1038/nri1706

45. Graham JB, Da CA, Lund JM. Regulatory T cells shape the resident memory $\mathrm{T}$ cell response to virus infection in the tissues. J Immunol (2014) 192:683-90. doi:10.4049/jimmunol.1202153

46. Aalaei-Andabili SH, Alavian SM. Regulatory T cells are the most important determinant factor of hepatitis B infection prognosis: a systematic review and meta-analysis. Vaccine (2012) 30:5595-602. doi:10.1016/j.vaccine.2012.06.063

47. Losikoff PT, Self AA, Gregory SH. Dendritic cells, regulatory T cells and the pathogenesis of chronic hepatitis C. Virulence (2012) 3:610-20. doi:10.4161/ viru. 21823

48. Self AA, Losikoff PT, Gregory SH. Divergent contributions of regulatory $\mathrm{T}$ cells to the pathogenesis of chronic hepatitis C. Hum Vaccin Immunother (2013) 9:1569-76. doi:10.4161/hv.24726 
49. Riezu-Boj JI, Larrea E, Aldabe R, Guembe L, Casares N, Galeano E, et al. Hepatitis C virus induces the expression of CCL17 and CCL22 chemokines that attract regulatory $\mathrm{T}$ cells to the site of infection. J Hepatol (2011) 54:422-31. doi:10.1016/j.jhep.2010.07.014

50. Chevalier MF, Weiss L. The split personality of regulatory T cells in HIV infection. Blood (2013) 121:29-37. doi:10.1182/blood-2012-07-409755

51. Moreno-Fernandez ME, Joedicke JJ, Chougnet CA. Regulatory T cells diminish HIV infection in dendritic cells - conventional CD4(+) T cell clusters. Front Immunol (2014) 5:199. doi:10.3389/fimmu.2014.00199

52. Nikolova M, Carriere M, Jenabian MA, Limou S, Younas M, Kok A, et al. CD39/adenosine pathway is involved in AIDS progression. PLoS Pathog (2011) 7:e1002110. doi:10.1371/journal.ppat.1002110

53. Schulze Zur WJ, Thomssen A, Hartjen P, Toth I, Lehmann C, Meyer-Olson $\mathrm{D}$, et al. Comprehensive analysis of frequency and phenotype of $\mathrm{T}$ regulatory cells in HIV infection: CD39 expression of FoxP3+ T regulatory cells correlates with progressive disease. J Virol (2011) 85:1287-97. doi:10.1128/JVI.01758-10

54. Johanns TM, Ertelt JM, Rowe JH, Way SS. Regulatory T cell suppressive potency dictates the balance between bacterial proliferation and clearance during persistent Salmonella infection. PLoS Pathog (2010) 6:e1001043. doi:10. 1371/journal.ppat.1001043

55. Monack DM. Helicobacter and Salmonella persistent infection strategies. Cold Spring Harb Perspect Med (2013) 3:a010348. doi:10.1101/cshperspect. a010348

56. Neill DR, Coward WR, Gritzfeld JF, Richards L, Garcia-Garcia FJ, Dotor J, et al. Density and duration of pneumococcal carriage is maintained by transforming growth factor betal and T regulatory cells. Am J Respir Crit Care Med (2014) 189:1250-9. doi:10.1164/rccm.201401-0128OC

57. Cook KW, Letley DP, Ingram RJ, Staples E, Skjoldmose H, Atherton JC, et al. CCL20/CCR6-mediated migration of regulatory $\mathrm{T}$ cells to the Helicobacter pylori-infected human gastric mucosa. Gut (2014) 63:1550-9. doi:10.1136/ gutjnl-2013-306253

58. Lina TT, Alzahrani S, Gonzalez J, Pinchuk IV, Beswick EJ, Reyes VE. Immune evasion strategies used by Helicobacter pylori. World J Gastroenterol (2014) 20:12753-66. doi:10.3748/wjg.v20.i36.12753

59. Round JL, Mazmanian SK. Inducible Foxp3+ regulatory T-cell development by a commensal bacterium of the intestinal microbiota. Proc Natl Acad Sci U $S$ A (2010) 107:12204-9. doi:10.1073/pnas.0909122107

60. Santos RC, Gomes-Santos AC, Garcias MT, de AM, Diniz LT, Mariadassou $\mathrm{M}$, et al. Local and systemic immune mechanisms underlying the anti-colitis effects of the dairy bacterium Lactobacillus delbrueckii. PLoS One (2014) 9:e85923. doi:10.1371/journal.pone.0085923

61. Nakamizo S, Egawa G, Honda T, Nakajima S, Belkaid Y, Kabashima K. Commensal bacteria and cutaneous immunity. Semin Immunopathol (2014) 37:73-80. doi:10.1007/s00281-014-0452-6

62. Marsland BJ, Gollwitzer ES. Host-microorganism interactions in lung diseases. Nat Rev Immunol (2014) 14:827-35. doi:10.1038/nri3769

63. Suffia IJ, Reckling SK, Piccirillo CA, Goldszmid RS, Belkaid Y. Infected siterestricted Foxp3+ natural regulatory $\mathrm{T}$ cells are specific for microbial antigens. J Exp Med (2006) 203:777-88. doi:10.1084/jem.20052056

64. Suffia I, Reckling SK, Salay G, Belkaid Y. A role for CD103 in the retention of CD4+CD25+ Treg and control of Leishmania major infection. J Immunol (2005) 174:5444-55. doi:10.4049/jimmunol.174.9.5444

65. Mendez S, Reckling SK, Piccirillo CA, Sacks D, Belkaid Y. Role for CD4(+) $\mathrm{CD} 25(+)$ regulatory $\mathrm{T}$ cells in reactivation of persistent leishmaniasis and control of concomitant immunity. J Exp Med (2004) 200:201-10. doi:10.1084/ jem.20040298

66. Belkaid Y, Piccirillo CA, Mendez S, Shevach EM, Sacks DL. CD4+CD25+ regulatory T cells control Leishmania major persistence and immunity. Nature (2002) 420:502-7. doi:10.1038/nature01152

67. Nagase H, Jones KM, Anderson CF, Noben-Trauth N. Despite increased CD4+Foxp3+ cells within the infection site, BALB/c IL-4 receptor-deficient mice reveal CD4+Foxp3-negative T cells as a source of IL-10 in Leishmania major susceptibility. J Immunol (2007) 179:2435-44. doi:10.4049/jimmunol. 179.4.2435

68. Campanelli AP, Roselino AM, Cavassani KA, Pereira MS, Mortara RA, Brodskyn CI, et al. CD4+CD25+ T cells in skin lesions of patients with cutaneous leishmaniasis exhibit phenotypic and functional characteristics of natural regulatory T cells. J Infect Dis (2006) 193:1313-22. doi:10.1086/502980
69. Hoseini SG, Javanmard SH, Zarkesh SH, Khamesipour A, Rafiei L, Karbalaie $\mathrm{K}$, et al. Regulatory T-cell profile in early and late lesions of cutaneous leishmaniasis due to Leishmania major. J Res Med Sci (2012) 17:513-8.

70. Bourreau E, Ronet C, Darcissac E, Lise MC, Sainte MD, Clity E, et al. Intralesional regulatory T-cell suppressive function during human acute and chronic cutaneous leishmaniasis due to Leishmania guyanensis. Infect Immun (2009) 77:1465-74. doi:10.1128/IAI.01398-08

71. Bourreau E, Ronet C, Darsissac E, Lise MC, Marie DS, Clity E, et al. In leishmaniasis due to Leishmania guyanensis infection, distinct intralesional interleukin-10 and Foxp3 mRNA expression are associated with unresponsiveness to treatment. J Infect Dis (2009) 199:576-9. doi:10.1086/ 596508

72. Hansen DS, Schofield L. Natural regulatory T cells in malaria: host or parasite allies? PLoS Pathog (2010) 6:e1000771. doi:10.1371/journal.ppat.1000771

73. Minigo G, Woodberry T, Piera KA, Salwati E, Tjitra E, Kenangalem E, et al. Parasite-dependent expansion of TNF receptor II-positive regulatory T cells with enhanced suppressive activity in adults with severe malaria. PLoS Pathog (2009) 5:e1000402. doi:10.1371/journal.ppat.1000402

74. Torcia MG, Santarlasci V, Cosmi L, Clemente A, Maggi L, Mangano VD, et al. Functional deficit of $\mathrm{T}$ regulatory cells in Fulani, an ethnic group with low susceptibility to Plasmodium falciparum malaria. Proc Natl Acad Sci U S A (2008) 105:646-51. doi:10.1073/pnas.0709969105

75. Todryk SM, Bejon P, Mwangi T, Plebanski M, Urban B, Marsh K, et al. Correlation of memory $\mathrm{T}$ cell responses against TRAP with protection from clinical malaria, and CD4 CD25 high T cells with susceptibility in Kenyans. PLoS One (2008) 3:e2027. doi:10.1371/journal.pone.0002027

76. Weinstock JV, Elliott DE. Helminth infections decrease host susceptibility to immune-mediated diseases. J Immunol (2014) 193:3239-47. doi:10.4049/ jimmunol.1400927

77. Sawant DV, Gravano DM, Vogel P, Giacomin P, Artis D, Vignali DA. Regulatory $\mathrm{T}$ cells limit induction of protective immunity and promote immune pathology following intestinal helminth infection. J Immunol (2014) 192:2904-12. doi:10.4049/jimmunol.1202502

78. George PJ, Anuradha R, Kumaran PP, Chandrasekaran V, Nutman TB, Babu S. Modulation of mycobacterial-specific Th1 and Th17 cells in latent tuberculosis by coincident hookworm infection. J Immunol (2013) 190:5161-8. doi:10. 4049/jimmunol.1203311

79. Babu S, Bhat SQ, Kumar NP, Jayantasri S, Rukmani S, Kumaran P, et al. Human type 1 and 17 responses in latent tuberculosis are modulated by coincident filarial infection through cytotoxic T lymphocyte antigen-4 and programmed death-1. J Infect Dis (2009) 200:288-98. doi:10.1086/599797

80. Abate E, Elias D, Getachew A, Alemu S, Diro E, Britton S, et al. Effects of albendazole on the clinical outcome and immunological responses in helminth co-infected tuberculosis patients: a double blind randomized clinical trial. Int J Parasitol (2014) 45(2-3):133-40. doi:10.1016/j.ijpara.2014.09.006

81. World Health Organization. Report of the global forum on elimination of leprosy as a public health problem. World Health Organization, Geneva, Switzerland. (2006).

82. Bobosha K, Wilson L, van Meijgaarden KE, Bekele Y, Zewdie M, Van Der Ploeg-Van Schip JJ, et al. T-cell regulation in lepromatous leprosy. PLoS Negl Trop Dis (2014) 8:e2773. doi:10.1371/journal.pntd.0002773

83. Fernandes C, Goncalves HS, Cabral PB, Pinto HC, Pinto MI, Camara LM. Increased frequency of CD4 and CD8 regulatory T cells in individuals under 15 years with multibacillary leprosy. PLoS One (2013) 8:e79072. doi:10.1371/ journal.pone.0079072

84. Palermo ML, Pagliari C, Trindade MA, Yamashitafuji TM, Duarte AJ, Cacere $\mathrm{CR}$, et al. Increased expression of regulatory $\mathrm{T}$ cells and down-regulatory molecules in lepromatous leprosy. Am J Trop Med Hyg (2012) 86:878-83. doi:10.4269/ajtmh.2012.12-0088

85. Saini C, Ramesh V, Nath I. Increase in TGF-beta secreting CD4(+)CD25(+) FOXP3(+) T regulatory cells in anergic lepromatous leprosy patients. PLoS Negl Trop Dis (2014) 8:e2639. doi:10.1371/journal.pntd.0002639

86. Kumar S, Naqvi RA, Ali R, Rani R, Khanna N, Rao DN. CD4+CD25+ T regs with acetylated FoxP3 are associated with immune suppression in human leprosy. Mol Immunol (2013) 56:513-20. doi:10.1016/j.molimm.2013.04.015

87. Callegaro-Filho D, Shrestha N, Burdick AE, Haslett PA. A potential role for complement in immune evasion by Mycobacterium leprae. J Drugs Dermatol (2010) 9:1373-82. 
88. Kraaij MD, Savage ND, van der Kooij SW, Koekkoek K, Wang J, van den Berg JM, et al. Induction of regulatory $\mathrm{T}$ cells by macrophages is dependent on production of reactive oxygen species. Proc Natl Acad Sci U S A (2010) 107:17686-91. doi:10.1073/pnas.1012016107

89. Moura DF, de Mattos KA, Amadeu TP, Andrade PR, Sales JS, Schmitz V, et al. CD163 favors Mycobacterium leprae survival and persistence by promoting anti-inflammatory pathways in lepromatous macrophages. Eur J Immunol (2012) 42:2925-36. doi:10.1002/eji.201142198

90. Kumar S, Naqvi RA, Ali R, Rani R, Khanna N, Rao DN. FoxP3 provides competitive fitness to $\mathrm{CD} 4(+) \mathrm{CD} 25(+) \mathrm{T}$ cells in leprosy patients via transcriptional regulation. Eur J Immunol (2014) 44:431-9. doi:10.1002/eji.201343649

91. Kumar S, Naqvi RA, Khanna N, Pathak P, Rao DN. Th3 immune responses in the progression of leprosy via molecular cross-talks of TGF-beta, CTLA-4 and Cbl-b. Clin Immunol (2011) 141:133-42. doi:10.1016/j.clim.2011.06.007

92. Paolino M, Thien CB, Gruber T, Hinterleitner R, Baier G, Langdon WY, et al. Essential role of E3 ubiquitin ligase activity in Cbl-b-regulated T cell functions. J Immunol (2011) 186:2138-47. doi:10.4049/jimmunol.1003390

93. Abbas AK. A network of regulatory pathways in lepromatous leprosy. Clin Immunol (2011) 141:127. doi:10.1016/j.clim.2011.08.007

94. Shafiani S, Tucker-Heard G, Kariyone A, Takatsu K, Urdahl KB. Pathogenspecific regulatory $\mathrm{T}$ cells delay the arrival of effector $\mathrm{T}$ cells in the lung during early tuberculosis. J Exp Med (2010) 207:1409-20. doi:10.1084/jem.20091885

95. Scott-Browne JP, Shafiani S, Tucker-Heard G, Ishida-Tsubota K, Fontenot JD, Rudensky AY, et al. Expansion and function of Foxp3-expressing T regulatory cells during tuberculosis. J Exp Med (2007) 204:2159-69. doi:10.1084/jem. 20062105

96. Kursar M, Koch M, Mittrucker HW, Nouailles G, Bonhagen K, Kamradt T, et al. Cutting edge: regulatory T cells prevent efficient clearance of Mycobacterium tuberculosis. J Immunol (2007) 178:2661-5. doi:10.4049/jimmunol.178. 5.2661

97. Shafiani S, Dinh C, Ertelt JM, Moguche AO, Siddiqui I, Smigiel KS, et al. Pathogen-specific Treg cells expand early during Mycobacterium tuberculosis infection but are later eliminated in response to interleukin-12. Immunity (2013) 38:1261-70. doi:10.1016/j.immuni.2013.06.003

98. Ottenhoff TH. New pathways of protective and pathological host defense to mycobacteria. Trends Microbiol (2012) 20(9):419-28. doi:10.1016/j.tim.2012. 06.002

99. Cooper AM. Cell-mediated immune responses in tuberculosis. Annu Rev Immunol (2009) 27:393-422. doi:10.1146/annurev.immunol.021908.132703

100. Ozeki Y, Sugawara I, Udagawa T, Aoki T, Osada-Oka M, Tateishi Y, et al. Transient role of $\mathrm{CD} 4+\mathrm{CD} 25+$ regulatory $\mathrm{T}$ cells in mycobacterial infection in mice. Int Immunol (2010) 22:179-89. doi:10.1093/intimm/dxp126

101. Chen CY, Huang D, Yao S, Halliday L, Zeng G, Wang RC, et al. IL-2 simultaneously expands Foxp3+ $\mathrm{T}$ regulatory and $\mathrm{T}$ effector cells and confers resistance to severe tuberculosis (TB): implicative Treg-T effector cooperation in immunity to TB. J Immunol (2012) 188:4278-88. doi:10.4049/jimmunol. 1101291

102. Gratz IK, Campbell DJ. Organ-specific and memory treg cells: specificity, development, function, and maintenance. Front Immunol (2014) 5:333. doi:10. 3389/fimmu.2014.00333

103. Guyot-Revol V, Innes JA, Hackforth S, Hinks T, Lalvani A. Regulatory T cells are expanded in blood and disease sites in patients with tuberculosis. Am J Respir Crit Care Med (2006) 173:803-10. doi:10.1164/rccm.200508-1294OC

104. Ribeiro-Rodrigues R, Resende CT, Rojas R, Toossi Z, Dietze R, Boom WH, et al. A role for $\mathrm{CD} 4+\mathrm{CD} 25+\mathrm{T}$ cells in regulation of the immune response during human tuberculosis. Clin Exp Immunol (2006) 144:25-34. doi:10.1111/ j.1365-2249.2006.03027.x

105. Chiacchio T, Casetti R, Butera O, Vanini V, Carrara S, Girardi E, et al. Characterization of regulatory T cells identified as CD4(+)CD25(high)CD39(+) in patients with active tuberculosis. Clin Exp Immunol (2009) 156:463-70. doi:10.1111/j.1365-2249.2009.03908.x

106. Singh A, Dey AB, Mohan A, Sharma PK, Mitra DK. Foxp3+ regulatory $\mathrm{T}$ cells among tuberculosis patients: impact on prognosis and restoration of antigen specific IFN-gamma producing T cells. PLoS One (2012) 7:e44728. doi:10.1371/journal.pone.0044728

107. Semple PL, Binder AB, Davids M, Maredza A, van Zyl-Smit RN, Dheda K. Regulatory $\mathrm{T}$ cells attenuate mycobacterial stasis in alveolar and blood-derived macrophages from patients with tuberculosis. Am J Respir Crit Care Med (2013) 187:1249-58. doi:10.1164/rccm.201210-1934OC
108. Burl S, Hill PC, Jeffries DJ, Holland MJ, Fox A, Lugos MD, et al. FOXP3 gene expression in a tuberculosis case contact study. Clin Exp Immunol (2007) 149:117-22. doi:10.1111/j.1365-2249.2007.03399.x

109. Joosten SA, van Meijgaarden KE, Savage ND, de Boer T, Triebel F, van der Wal $\mathrm{A}$, et al. Identification of a human CD8+ regulatory $\mathrm{T}$ cell subset that mediates suppression through the chemokine CC chemokine ligand 4. Proc Natl Acad Sci U S A (2007) 104:8029-34. doi:10.1073/pnas.0702257104

110. Joosten SA, van Meijgaarden KE, van Weeren PC, Kazi F, Geluk A, Savage ND, et al. Mycobacterium tuberculosis peptides presented by HLA-E molecules are targets for human CD8 T-cells with cytotoxic as well as regulatory activity. PLoS Pathog (2010) 6:e1000782. doi:10.1371/journal.ppat.1000782

111. Meijgaarden KE, Haks MC, Caccamo N, Dieli F, Ottenhoff TH, Joosten SA. Human CD8+ T-cells recognizing peptides from Mycobacterium tuberculosis (Mtb) presented by HLA-E have an unorthodox Th2-like, multifunctional, Mtb inhibitory phenotype and represent a novel human T-cell subset. PLoS Pathog (2015) 11(3):e1004671. doi:10.1371/journal.ppat.1004671

112. Lim HJ, Park JS, Cho YJ, Yoon HI, Park KU, Lee CT, et al. CD4(+)FoxP3(+) $\mathrm{T}$ regulatory cells in drug-susceptible and multidrug-resistant tuberculosis. Tuberculosis (Edinb) (2013) 93:523-8. doi:10.1016/j.tube.2013.06.001

113. Pinheiro RO, de Oliveira EB, Dos SG, Sperandio da Silva GM, de Andrade Silva BJ, Teles RM, et al. Different immunosuppressive mechanisms in multidrug-resistant tuberculosis and non-tuberculous mycobacteria patients. Clin Exp Immunol (2013) 171:210-9. doi:10.1111/cei.12007

114. Marin ND, Paris SC, Velez VM, Rojas CA, Rojas M, Garcia LF. Regulatory T cell frequency and modulation of IFN-gamma and IL-17 in active and latent tuberculosis. Tuberculosis (Edinb) (2010) 90:252-61. doi:10.1016/j.tube.2010. 05.003

115. Kim K, Perera R, Tan DB, Fernandez S, Seddiki N, Waring J, et al. Circulating mycobacterial-reactive CD4+ T cells with an immunosuppressive phenotype are higher in active tuberculosis than latent tuberculosis infection. Tuberculosis (Edinb) (2014) 94:494-501. doi:10.1016/j.tube.2014.07.002

116. Place S, Verscheure V, de San N, Hougardy JM, Schepers K, Dirix V, et al. Heparin-binding, hemagglutinin-specific IFN-gamma synthesis at the site of infection during active tuberculosis in humans. Am J Respir Crit Care Med (2010) 182:848-54. doi:10.1164/rccm.201001-0083OC

117. Rozot V, Vigano S, Mazza-Stalder J, Idrizi E, Day CL, Perreau M, et al. Mycobacterium tuberculosis-specific CD8+ T cells are functionally and phenotypically different between latent infection and active disease. Eur J Immunol (2013) 43:1568-77. doi:10.1002/eji.201243262

118. Lewinsohn DA, Heinzel AS, Gardner JM, Zhu L, Alderson MR, Lewinsohn DM. Mycobacterium tuberculosis-specific CD8+ T cells preferentially recognize heavily infected cells. Am J Respir Crit Care Med (2003) 168:1346-52. doi:10.1164/rccm.200306-837OC

119. Silva BD, Trentini MM, da Costa AC, Kipnis A, Junqueira-Kipnis AP. Different phenotypes of $\mathrm{CD} 8+\mathrm{T}$ cells associated with bacterial load in active tuberculosis. Immunol Lett (2014) 160:23-32. doi:10.1016/j.imlet.2014.03.009

120. Cyktor JC, Carruthers B, Beamer GL, Turner J. Clonal expansions of CD8+ $\mathrm{T}$ cells with IL-10 secreting capacity occur during chronic Mycobacterium tuberculosis infection. PLoS One (2013) 8:e58612. doi:10.1371/journal.pone. 0058612

121. Garcia Jacobo RE, Serrano CJ, Enciso Moreno JA, Gaspar RO, Trujillo Ochoa JL, Uresti Rivera EE, et al. Analysis of Th1, Th17 and regulatory T cells in tuberculosis case contacts. Cell Immunol (2014) 289:167-73. doi:10.1016/j. cellimm.2014.03.010

122. Hopewell PC. Clinical Features of Tuberculosis. In: Kaufmann SH, van Helden P, editors. Handbook of Tuberculosis: Clinics, Diagnostics, Therapy and Epidemiology. Weinheim: Wiley-VCH Verlag GmbH \& Co (2008). p. 89-114.

123. Sharma PK, Saha PK, Singh A, Sharma SK, Ghosh B, Mitra DK. FoxP3+ regulatory $\mathrm{T}$ cells suppress effector $\mathrm{T}$-cell function at pathologic site in miliary tuberculosis. Am J Respir Crit Care Med (2009) 179:1061-70. doi:10.1164/ rccm.200804-529OC

124. de Almeida AS, Fiske CT, Sterling TR, Kalams SA. Increased frequency of regulatory $\mathrm{T}$ cells and $\mathrm{T}$ lymphocyte activation in persons with previously treated extrapulmonary tuberculosis. Clin Vaccine Immunol (2012) 19:45-52. doi:10.1128/CVI.05263-11

125. Wu C, Zhou Q, Qin XJ, Qin SM, Shi HZ. CCL22 is involved in the recruitment of CD4+CD25 high T cells into tuberculous pleural effusions. Respirology (2010) 15:522-9. doi:10.1111/j.1440-1843.2010.01719.x 
126. Geffner L, Basile JI, Yokobori N, Sabio YG, Musella R, Castagnino J, et al. $\mathrm{CD} 4(+) \mathrm{CD} 25$ (high) forkhead box protein $3(+)$ regulatory $\mathrm{T}$ lymphocytes suppress interferon-gamma and CD107 expression in CD4(+) and CD8(+) T cells from tuberculous pleural effusions. Clin Exp Immunol (2014) 175:235-45. doi:10.1111/cei.12227

127. Ye ZJ, Zhou Q, Du RH, Li X, Huang B, Shi HZ. Imbalance of Th17 cells and regulatory T cells in tuberculous pleural effusion. Clin Vaccine Immunol (2011) 18:1608-15. doi:10.1128/CVI.05214-11

128. Yuan ML, Tong ZH, Jin XG, Zhang JC, Wang XJ, Ma WL, et al. Regulation of $\mathrm{CD} 4(+) \mathrm{T}$ cells by pleural mesothelial cells via adhesion molecule-dependent mechanisms in tuberculous pleurisy. PLoS One (2013) 8:e74624. doi:10.1371/ journal.pone.0074624

129. Rahman S, Gudetta B, Fink J, Granath A, Ashenafi S, Aseffa A, et al. Compartmentalization of immune responses in human tuberculosis: few CD8+ effector $\mathrm{T}$ cells but elevated levels of FoxP3+ regulatory t cells in the granulomatous lesions. Am J Pathol (2009) 174:2211-24. doi:10.2353/ajpath.2009.080941

130. Saenz B, Hernandez-Pando R, Fragoso G, Bottasso O, Cardenas G. The dual face of central nervous system tuberculosis: a new Janus Bifrons? Tuberculosis (Edinb) (2013) 93:130-5. doi:10.1016/j.tube.2012.11.011

131. Tan DB, Yong YK, Tan HY, Kamarulzaman A, Tan LH, Lim A, et al. Immunological profiles of immune restoration disease presenting as mycobacterial lymphadenitis and cryptococcal meningitis. HIV Med (2008) 9:307-16. doi:10. 1111/j.1468-1293.2008.00565.x

132. Zaidi I, Peterson K, Jeffries D, Whittle H, de ST, Rowland-Jones S, et al. Immune reconstitution inflammatory syndrome and the influence of $\mathrm{T}$ regulatory cells: a cohort study in the Gambia. PLoS One (2012) 7:e39213. doi:10. 1371/journal.pone. 0039213

133. Haddow LJ, Dibben O, Moosa MY, Borrow P, Easterbrook PJ. Circulating inflammatory biomarkers can predict and characterize tuberculosis-associated immune reconstitution inflammatory syndrome. AIDS (2011) 25:1163-74. doi:10.1097/QAD.0b013e3283477d67

134. Seddiki N, Sasson SC, Santner-Nanan B, Munier M, van BD, Ip S, et al. Proliferation of weakly suppressive regulatory CD4+ T cells is associated with over-active CD4+ T-cell responses in HIV-positive patients with mycobacterial immune restoration disease. Eur J Immunol (2009) 39:391-403. doi:10.1002/ eji.200838630

135. Boussiotis VA, Tsai EY, Yunis EJ, Thim S, Delgado JC, Dascher CC, et al. IL-10producing $\mathrm{T}$ cells suppress immune responses in anergic tuberculosis patients. J Clin Invest (2000) 105:1317-25. doi:10.1172/JCI9918

136. Delgado JC, Tsai EY, Thim S, Baena A, Boussiotis VA, Reynes JM, et al. Antigen-specific and persistent tuberculin anergy in a cohort of pulmonary tuberculosis patients from rural Cambodia. Proc Natl Acad Sci U S A (2002) 99:7576-81. doi:10.1073/pnas.062056099

137. Ranjbar S, Ly N, Thim S, Reynes JM, Goldfeld AE. Mycobacterium tuberculosis recall antigens suppress HIV-1 replication in anergic donor cells via CD8+ $\mathrm{T}$ cell expansion and increased IL-10 levels. J Immunol (2004) 172:1953-9. doi:10.4049/jimmunol.172.3.1953

138. Hougardy JM, Place S, Hildebrand M, Drowart A, Debrie AS, Locht C, et al. Regulatory $\mathrm{T}$ cells depress immune responses to protective antigens in active tuberculosis. Am J Respir Crit Care Med (2007) 176:409-16. doi:10.1164/rccm. 200701-084OC

139. de Cassan SC, Pathan AA, Sander CR, Minassian A, Rowland R, Hill AV, et al. Investigating the induction of vaccine-induced Th17 and regulatory $\mathrm{T}$ cells in healthy, Mycobacterium bovis BCG-immunized adults vaccinated with a new tuberculosis vaccine, MVA85A. Clin Vaccine Immunol (2010) 17:1066-73. doi:10.1128/CVI.00047-10

140. Griffiths KL, Pathan AA, Minassian AM, Sander CR, Beveridge NE, Hill $\mathrm{AV}$, et al. Th1/Th17 cell induction and corresponding reduction in ATP consumption following vaccination with the novel Mycobacterium tuberculosis vaccine MVA85A. PLoS One (2011) 6:e23463. doi:10.1371/journal.pone. 0023463

141. Pinheiro MB, Antonelli LR, Sathler-Avelar R, Vitelli-Avelar DM, Spindola-deMiranda S, Guimaraes TM, et al. CD4-CD8-alphabeta and gammadelta T cells display inflammatory and regulatory potentials during human tuberculosis. PLoS One (2012) 7:e50923. doi:10.1371/journal.pone.0050923

142. Jackson-Sillah D, Cliff JM, Mensah GI, Dickson E, Sowah S, Tetteh JK, et al. Recombinant ESAT-6-CFP10 fusion protein induction of Th1/Th2 cytokines and FoxP3 expressing Treg cells in pulmonary TB. PLoS One (2013) 8:e68121. doi:10.1371/journal.pone.0068121
143. He XY, Xiao L, Chen HB, Hao J, Li J, Wang YJ, et al. T regulatory cells and Th1/Th2 cytokines in peripheral blood from tuberculosis patients. Eur J Clin Microbiol Infect Dis (2010) 29:643-50. doi:10.1007/s10096-010-0908-0

144. Feruglio SL, Tonby K, Kvale D, Dyrhol-Riise AM. Early dynamics of $\mathrm{T}$ helper cell cytokines and $\mathrm{T}$ regulatory cells in response to treatment of active Mycobacterium tuberculosis infection. Clin Exp Immunol (2014) 179(3):454-65. doi:10.1111/cei.12468

145. Sprengers D, Stoop JN, Binda RS, Kusters JG, Haagmans BL, Carotenuto P, et al. Induction of regulatory T-cells and interleukin-10-producing cells in non-responders to pegylated interferon-alpha therapy for chronic hepatitis $B$. Antivir Ther (2007) 12:1087-96.

146. Ndure J, Flanagan KL. Targeting regulatory $\mathrm{T}$ cells to improve vaccine immunogenicity in early life. Front Microbiol (2014) 5:477. doi:10.3389/fmicb. 2014.00477

147. Ha TY, Waksman BH, Treffers HP. The thymic suppressor cell. I. Separation of subpopulations with suppressor activity. J Exp Med (1974) 139:13-23. doi:10. 1084/jem.139.1.13

148. Marchant A, Goetghebuer T, Ota MO, Wolfe I, Ceesay SJ, de Groote D, et al. Newborns develop a Th1-type immune response to Mycobacterium bovis Bacillus Calmette-Guerin vaccination. J Immunol (1999) 163:2249-55.

149. Hussey GD, Watkins ML, Goddard EA, Gottschalk S, Hughes EJ, Iloni K, et al. Neonatal mycobacterial specific cytotoxic T-lymphocyte and cytokine profiles in response to distinct BCG vaccination strategies. Immunology (2002) 105:314-24. doi:10.1046/j.1365-2567.2002.01366.x

150. Kaufmann SH. Tuberculosis vaccines: time to think about the next generation. Semin Immunol (2013) 25:172-81. doi:10.1016/j.smim.2013.04.006

151. Hanekom WA. The immune response to BCG vaccination of newborns. Ann N Y Acad Sci (2005) 1062:69-78. doi:10.1196/annals.1358.010

152. Akkoc T, Aydogan M, Yildiz A, Karakoc-Aydiner E, Eifan A, Keles S, et al. Neonatal BCG vaccination induces IL-10 production by CD4+ CD25+ T cells Pediatr Allergy Immunol (2010) 21:1059-63. doi:10.1111/j.1399-3038.2010. 01051.x

153. Li L, Qiao D, Zhang X, Liu Z, Wu C. The immune responses of central and effector memory BCG-specific CD4+ T cells in BCG-vaccinated PPD+ donors were modulated by Treg cells. Immunobiology (2011) 216:477-84. doi:10.1016/ j.imbio.2010.09.003

154. Boer MC, van Meijgaarden KE, Joosten SA, Ottenhoff TH. CD8+ regulatory $\mathrm{T}$ cells, and not $\mathrm{CD} 4+\mathrm{T}$ cells, dominate suppressive phenotype and function after in vitro live Mycobacterium bovis-BCG activation of human cells. PLoS One (2014) 9:e94192. doi:10.1371/journal.pone.0094192

155. Boer MC, van Meijgaarden KE, Bastid J, Ottenhoff TH, Joosten SA. CD39 is involved in mediating suppression by Mycobacterium bovis BCG-activated human CD8(+) CD39(+) regulatory T cells. Eur J Immunol (2013) 43:1925-32. doi:10.1002/eji.201243286

156. Day CL, Tameris M, Mansoor N, van RM, de KM, Geldenhuys H, et al. Induction and regulation of T-cell immunity by the novel tuberculosis vaccine M72/AS01 in South African adults. Am J Respir Crit Care Med (2013) 188:492-502. doi:10.1164/rccm.201208-1385OC

157. Matsumiya M, Stylianou E, Griffiths K, Lang Z, Meyer J, Harris SA, et al. Roles for Treg expansion and HMGB1 signaling through the TLR1-2-6 axis in determining the magnitude of the antigen-specific immune response to MVA85A. PLoS One (2013) 8:e67922. doi:10.1371/journal.pone.0067922

158. Matsumiya M, Harris SA, Satti I, Stockdale L, Tanner R, O'Shea MK, et al. Inflammatory and myeloid-associated gene expression before and one day after infant vaccination with MVA85A correlates with induction of a T cell response. BMC Infect Dis (2014) 14:314. doi:10.1186/ 1471-2334-14-314

159. Andersen P, Doherty TM. The success and failure of BCG - implications for a novel tuberculosis vaccine. Nat Rev Microbiol (2005) 3:656-62. doi:10.1038/ nrmicro1211

160. Coleman MM, Keane J, Mills KH. Editorial: Tregs and BCG - dangerous liaisons in TB. J Leukoc Biol (2010) 88:1067-9. doi:10.1189/jlb.0710419

161. Ho P, Wei X, Seah GT. Regulatory T cells induced by Mycobacterium chelonae sensitization influence murine responses to bacille Calmette-Guerin. J Leukoc Biol (2010) 88:1073-80. doi:10.1189/jlb.0809582

162. Beverley P, Ronan E, Lee L, Arnold I, Bolinger B, Powrie F, et al. Environmental effects on protection against Mycobacterium tuberculosis after immunization with Ad85A. Vaccine (2013) 31:1086-93. doi:10.1016/j.vaccine. 2012.12.024 
163. Perry S, Hussain R, Parsonnet J. The impact of mucosal infections on acquisition and progression of tuberculosis. Mucosal Immunol (2011) 4:246-51. doi:10.1038/mi.2011.11

164. Elias D, Britton S, Aseffa A, Engers H, Akuffo H. Poor immunogenicity of BCG in helminth infected population is associated with increased in vitro TGF-beta production. Vaccine (2008) 26:3897-902. doi:10.1016/j.vaccine. 2008.04.083

165. Lacan G, Dang H, Middleton B, Horwitz MA, Tian J, Melega WP, et al. Bacillus Calmette-Guerin vaccine-mediated neuroprotection is associated with regulatory T-cell induction in the 1-methyl-4-phenyl-1,2,3,6-tetrahydropyridine mouse model of Parkinson's disease. J Neurosci Res (2013) 91:1292-302. doi:10.1002/jnr.23253

166. Lee J, Reinke EK, Zozulya AL, Sandor M, Fabry Z. Mycobacterium bovis bacille Calmette-Guerin infection in the CNS suppresses experimental autoimmune encephalomyelitis and Th17 responses in an IFN-gamma-independent manner. J Immunol (2008) 181:6201-12. doi:10.4049/jimmunol.181.9.6201

167. Kim YJ, Kim HJ, Kang MJ, Yu HS, Seo JH, Kim HY, et al. Bacillus CalmetteGuerin suppresses asthmatic responses via CD4(+)CD25(+) regulatory T cells and dendritic cells. Allergy Asthma Immunol Res (2014) 6:201-7. doi:10.4168/ aair.2014.6.3.201

168. Lagranderie M, Kluge C, Kiefer-Biasizzo H, Abolhassani M, Nahori MA, Fitting C, et al. Mycobacterium bovis Bacillus Calmette-Guerin killed by extended freeze-drying reduces colitis in mice. Gastroenterology (2011) 141(642-52):652. doi:10.1053/j.gastro.2011.05.002

169. Andrieu JM, Chen S, Lai C, Guo W, Lu W. Mucosal SIV vaccines comprising inactivated virus particles and bacterial adjuvants induce CD8(+) T-regulatory cells that suppress SIV-positive CD4(+) T-cell activation and prevent SIV infection in the macaque model. Front Immunol (2014) 5:297. doi:10.3389/ fimmu.2014.00297

170. Bhattacharya D, Dwivedi VP, Maiga M, Maiga M, Van KL, Bishai WR, et al. Small molecule-directed immunotherapy against recurrent infection by Mycobacterium tuberculosis. J Biol Chem (2014) 289:16508-15. doi:10.1074/ jbc.M114.558098

171. Bhattacharya D, Dwivedi VP, Kumar S, Reddy MC, Kaer LV, Moodley P, et al. Simultaneous inhibition of T helper 2 and $\mathrm{T}$ regulatory cell differentiation by small molecules enhances Bacillus Calmette-Guerin vaccine efficacy against tuberculosis. J Biol Chem (2014) 289(48):33404-11. doi:10.1074/jbc.M114 600452

172. Pitt JM, Stavropoulos E, Redford PS, Beebe AM, Bancroft GJ, Young DB, et al. Blockade of IL-10 signaling during Bacillus Calmette-Guerin vaccination enhances and sustains Th1, Th17, and innate lymphoid IFN-gamma and IL17 responses and increases protection to Mycobacterium tuberculosis infection. J Immunol (2012) 189:4079-87. doi:10.4049/jimmunol.1201061

173. Dhiman R, Periasamy S, Barnes PF, Jaiswal AG, Paidipally P, Barnes AB, et al. $\mathrm{NK} 1.1+$ cells and IL-22 regulate vaccine-induced protective immunity against challenge with Mycobacterium tuberculosis. J Immunol (2012) 189:897-905. doi:10.4049/jimmunol.1102833

174. Jaron B, Maranghi E, Leclerc C, Majlessi L. Effect of attenuation of Treg during BCG immunization on anti-mycobacterial Th1 responses and protection against Mycobacterium tuberculosis. PLoS One (2008) 3:e2833. doi:10.1371/ journal.pone.0002833

175. Berod L, Stuve P, Varela F, Behrends J, Swallow M, Kruse F, et al. Rapid rebound of the Treg compartment in DEREG mice limits the impact of Treg depletion on mycobacterial burden, but prevents autoimmunity. PLoS One (2014) 9:e102804. doi:10.1371/journal.pone.0102804

176. Bayry J, Tchilian EZ, Davies MN, Forbes EK, Draper SJ, Kaveri SV, et al. In silico identified CCR4 antagonists target regulatory $\mathrm{T}$ cells and exert adjuvant activity in vaccination. Proc Natl Acad Sci U S A (2008) 105:10221-6. doi:10.1073/pnas.0803453105

177. Mills KH. Designer adjuvants for enhancing the efficacy of infectious disease and cancer vaccines based on suppression of regulatory $\mathrm{T}$ cell induction. Immunol Lett (2009) 122:108-11. doi:10.1016/j.imlet.2008.11.007

Conflict of Interest Statement: The authors declare that the research was conducted in the absence of any commercial or financial relationships that could be construed as a potential conflict of interest.

Copyright (c) 2015 Boer, Joosten and Ottenhoff. This is an open-access article distributed under the terms of the Creative Commons Attribution License (CC BY). The use, distribution or reproduction in other forums is permitted, provided the original author(s) or licensor are credited and that the original publication in this journal is cited, in accordance with accepted academic practice. No use, distribution or reproduction is permitted which does not comply with these terms. 